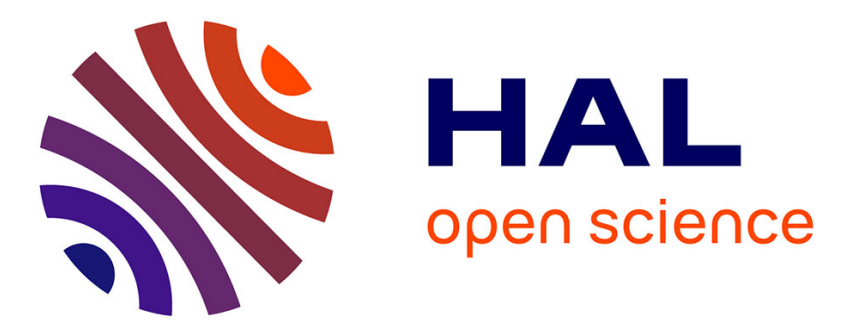

\title{
Optimal adaptation strategies to face shocks on groundwater resources
}

\author{
J. de Frutos Cachorro, K. Erdlenbruch, M. Tidball
}

\section{To cite this version:}

J. de Frutos Cachorro, K. Erdlenbruch, M. Tidball. Optimal adaptation strategies to face shocks on groundwater resources. Journal of Economic Dynamics and Control, 2014, 40, p. 134 - p. 153. 10.1016/j.jedc.2014.01.005 . hal-01006544

\section{HAL Id: hal-01006544 https://hal.science/hal-01006544}

Submitted on 16 Jun 2014

HAL is a multi-disciplinary open access archive for the deposit and dissemination of scientific research documents, whether they are published or not. The documents may come from teaching and research institutions in France or abroad, or from public or private research centers.
L'archive ouverte pluridisciplinaire HAL, est destinée au dépôt et à la diffusion de documents scientifiques de niveau recherche, publiés ou non, émanant des établissements d'enseignement et de recherche français ou étrangers, des laboratoires publics ou privés. 


\title{
Optimal adaptation strategies to face shocks on groundwater resources. ${ }^{*}$
}

\author{
Julia de Frutos Cachorroł Katrin Erdlenbruch $\$$ Mabel Tidball ${ }^{\S}$
}

\begin{abstract}
We consider an exogenous and reversible shock to a groundwater resource, namely a decrease in the recharge rate of the aquifer. We compare optimal extraction paths and the social costs of optimal adaptation in two cases: under certainty, i.e. when the date of occurrence of the shock is known, and under uncertainty, when the date of occurrence of the shock is a random variable. We show that an increase in uncertainty leads to a decrease in precautionary behavior in the short run and to an increase in precautionary behavior in the long run. We apply our model to the particular case of the Western la Mancha aquifer in Spain. We show that, in this context, it is advantageous for the water agency to acquire information on the date of the shock, especially for high-intensity and intermediate-risk events.
\end{abstract}

JEL classification: C61,Q25.

Key words: Groundwater resource, optimal behavior, exogenous shock, uncertainty.

\section{Introduction}

Periods of low precipitation may lead to insufficient filling of groundwater resources and pose challenges for existing management rules (see Amigues (2006) [1], Zilberman and al. (2003) [20]). This problem may become even more acute in the context of global warming. Moreover, the evolution of the natural system may be subject to abrupt changes that can be qualified as "regime shifts". Adaptation to such shifts hinges crucially on the available information about the nature of the change, such as its date and its intensity. In this paper, we address the problem of regime shifts in the context of groundwater management and identify the circumstances in which information on the date and intensity of the shock

\footnotetext{
${ }^{*}$ The authors acknowledge financial support from the ANR RISECO project ANR-08-JCJC-0074-01.

${ }^{\dagger}$ INRA, UMR 1135 LAMETA, 2 Place Viala, 34060 Montpellier cedex 1, France, mail: defrutos@supagro.inra.fr. IRSTEA, UMR G-EAU, F-34000 Montpellier, France.

${ }^{\ddagger}$ IRSTEA, UMR G-EAU, F-34000 Montpellier, France.

${ }^{\S}$ INRA, UMR 1135 LAMETA, F-34000 Montpellier, France.
} 
is particularly important for a water manager.

We examine a case in which a common groundwater resource, used by several farmers for irrigation, is subject to dry periods. We use a simple groundwater model, the Gisser and Sanchez (1990) [10] model (for similar model frameworks, see for example Cummings (1971) [4] or Roseta-Palma (2003, 2002) [14], [13]), in which we introduce a sudden change in the dynamics of the resource. Such a shock may occur due to a decrease in mean precipitation that leads to a decrease in the recharge of the aquifer, or it may correspond to the abstraction of a certain amount of water that is dedicated to other uses in the case of a drought, such as filling drinking water reservoirs. ${ }^{1}$ The aquifer is managed by a social planner, the water agency, who wishes to adapt as well as possible to these shocks. We characterize both the hydrological and the economic consequences of the shock by comparing short and long-run levels of resource stocks and social welfare.

In particular, we are interested in discussing the effect of information knowledge on the optimal management of the water resource. To this end, we introduce two types of shocks in our model: a deterministic shock at a given date and a random shock that may occur with a certain probability. This allows us to discuss the impact of uncertainty on precautionary behavior and management efficiency.

First, when the date of the shock is known, intuitively, one might think that the water agency would prepare for the event by applying a more careful extraction strategy. However, our results contradict our intuition and more water is extracted in the short term. Such a result can already be found in the literature (see Di Maria et al. (2012) [7]), in the context of polluting resources, where the phenomenon is known as the "announcement effect" or the "abundance effect". However, using a numerical example, we show that nonmonotonic extraction behavior is possible in the short term, when the value of the shock is important and when it takes place later in time. Second, when the date of the shock is a random variable, some hints about possible solutions can be derived from the literature on catastrophic events, in the context of groundwater resource management (see Tsur and Zemel (2012, 2004, 1995) [18], [17], [15]) and pollution control (see Brozovic and Schlenker (2011) [2], Clarke and Reed (1994) [3], de Zeeuw and Zemel (2012) [6], Tsur and Zemel (1996) [16] and Zemel (2012) [19]).

In [18], Tsur and Zemel (2012) review the literature on the variety of forms in which uncertainty enters resource management problems. They distinguish two types of uncertainty: ignorance uncertainty, due to the limited knowledge of certain parameters of the resource (for example the recharge or instantaneous benefit may undergo an abrupt shift when the stock process crosses some unknown threshold) and exogenous uncertainty due

\footnotetext{
${ }^{1}$ In reality, such changes would not occur at a precise date but rather over some period of time. In addition, a decrease in the recharge rate requires a period of time in order to have a real impact on the aquifer. For simplicity, we consider here that the effect of the shock is immediate.
} 
to random environmental elements (for example weather variability) ${ }^{2}$. Depending on the type of uncertainty considered, the relationship between precautionary behavior and an increase in uncertainty can vary. Some studies show that an increase in uncertainty leads to non-monotonic changes in precautionary behavior (see Brozovic and Schlenker (2011) [2], Clarke and Reed (1994) [3], Zemel (2012) [19]), while others show that an increase in uncertainty leads to a decrease in precautionary behavior (see Tsur and Zemel (2004, 1995) [17]), [15]). Still others conclude that an increase in uncertainty leads to an increase in precautionary behavior (see de Zeeuw and Zemel (2012) [6], Tsur and Zemel (2004) [17]). For example, Brozovic and Schlenker (2011) in [2] and Zemel (2012) in [19] found a non-monotonic relation when several sources of uncertainty are combined. Tsur and Zemel (2004) proved that an increase in uncertainty leads to more intensive extraction in the case of irreversible exogenous events. ${ }^{3}$ In contrast, they showed that more precautionary behavior is applied in the long run in the case of reversible exogenous events or endogenous events. Moreover, in [6], de Zeeuw and Zemel (2012) proved that the introduction of a random jump in the damage function of a pollution control model leads to more precautionary behavior, both in the case of endogenous events and irreversible exogenous events.

In this paper, we study reversible exogenous events and analyze the relationship between the characteristics of the shock and adaptive behavior in the short run and the long run. We are especially interested in the exogenous uncertainty of the time parameter $\mathrm{T}$, when $\mathrm{T}$ is a random variable whose realization marks the occurrence of an event. In this case, Tsur and Zemel argue that, compared with the risk free situation ${ }^{4}$, the optimal policy entails more aggressive exploitation in the short term and more conservative extraction after the occurrence of the event. We show that although our results correspond to the solutions found by Tsur and Zemel (2012) in [18], our paper differs from theirs in several ways: First, Tsur and Zemel analyze catastrophic events (such as saltwater intrusion) which render further use of the resource impossible (unless restoration is undertaken). We focus on an event that does not hinder further exploitation. Second, we add to the exogenous uncertainty of the time parameter, an abrupt shift in the dynamics of the resource, and not in the objective function ${ }^{5}$. Third, we compare optimal adaptation behavior for different uncertainty scenarios, and do not only compare the risk-free and the uncertainty situation. Finally, we illustrate the economic implications of the shock with a numerical example.

We apply our model to the Western la Mancha aquifer in the South of Spain. In this area, the state of groundwater resources has significant implications for the future provi-

\footnotetext{
${ }^{2}$ Similar concepts are those of endogenous and exogenous events used by Tsur and Zemel (1995) in [15].

${ }^{3}$ In [17], they define that an event is irreversible when its occurrence renders the resource obsolete, and is reversible when restoration is possible at a cost.

${ }^{4}$ The risk-free situation corresponds to our initial groundwater problem in the absence of shock.

${ }^{5}$ In Tsur and Zemel's articles, for reversible events, a penalty function is added to take into account restorations costs.
} 
sion of important ecosystem services (see Esteban and Albiac (2011) [8] and Esteban and Dinar (2012) [9] for details). The average annual groundwater recharge in this aquifer is 360 million cubic meters. In recent decades, the aquifer has been subject to numerous droughts. Since 1999, the recharge rate has decreased by approximately 100 millions cubic meters, leading to an estimated decrease of 3000 million cubic meters over the past three decades (see López-Gunn [12]). In the numerical simulations, we analyze the impact of such shocks, considering variations in the recharge rates of the same magnitude as past variations (and not possible future variations caused by climate change). We thus analyze a lower benchmark problem. Even though we assume that the water agency does its best to adapt to these shocks, we show that the costs to society are high, and may reach several million Euros. In addition, we wish to know whether or not the water agency should try to forecast the date of the shock. We show that it is always advantageous for the water agency to acquire additional information about the date of the shock. Moreover, this information is more useful when the shock is more intense and when it takes place in the medium run. Finally, we confirm that it is always better for the water agency to be prepared to adapt, with or without knowledge of the date of the shock, than not to prepare for the shock at all.

This paper is organized as follows. In section 2, we briefly describe the underlying Gisser and Sanchez model. We then introduce an exogenous shock in the recharge rate and derive some theoretical results on optimal adaptation strategies to face this shock. In section 3 , we provide a numerical illustration in which we analyze optimal adaptation behavior and the impact of the shock on social welfare in the short run and in the long run. Finally, in section 4, we conclude and make some suggestions for future research.

\section{The model}

We base our analysis on the groundwater extraction model by Gisser and Sanchez, (see [10]), where $G(t)$ and $g(t)$ are respectively the stock (in volume) ${ }^{6}$ and water pumping rate of the aquifer as a function of time ${ }^{7}$. We assume that

$$
g=a-b p
$$

is a linear function that represents the demand for irrigation water, where $p$ is the price of water, and $a, b$ are coefficients of the demand function, with $a, b>0$.

We consider a linear cost function for extractions costs:

$$
\bar{C}=z-c G
$$

\footnotetext{
${ }^{6} \mathrm{G}$ corresponds to the volume of water, and is calculated by multiplying $\mathrm{H}$, the height of the aquifer, by $A^{*} \mathrm{~S}$, where $\mathrm{A}$ is the area of the aquifer and $\mathrm{S}$ is the storativity coefficient.

${ }^{7}$ We omit the time indicator in all the following equations, whenever this is possible without causing misunderstandings, in order to make the equations easier to read.
} 
where $z, c$ are coefficients of the linear cost function $(z>0, c>0): z$ includes fixed costs and maximimum pumping cost and $c$ represents marginal pumping cost. ${ }^{8}$

The dynamics of the aquifer,

$$
\dot{G}=-(1-\alpha) g+r
$$

depend on hydrological characteristics of the aquifer, where $r$ is the recharge rate and $\alpha$ is the return flow coefficient, with $\alpha \in[0,1)$.

The farmers' total income, using the agricultural surface characterized by the demand function of water, equation (1)), is then:

$$
\int_{g} p(x) d x=\int_{g} \frac{a-x}{b} d x=\frac{a}{b} g-\frac{1}{2 b} g^{2} .
$$

The problem for the social planner is to maximize social welfare, that is the present value of farmers' private income, with $\rho$, the discount rate, taking into account the dynamics of the aquifer (see equation (3)), and subject to the initial conditions and positivity constraints:

$$
\max _{g(.)} \int_{0}^{\infty} \quad F(G, g) \quad \mathrm{e}^{-\rho \mathrm{t}} \mathrm{dt}
$$

where

$$
\begin{gathered}
F(G, g)=\frac{a}{b} g-\frac{1}{2 b} g^{2}-(z-c G) g, \\
\dot{G}=-(1-\alpha) g+r, \\
G(0)=G_{0} \quad \text { given, } \\
g \geq 0 \quad G \geq 0 .
\end{gathered}
$$

The full resolution of the problem is given in Appendix (A.1).

In the following sections, we introduce an exogenous shock in our initial model, i.e. a decrease in the recharge rate of the aquifer at the date $t_{a}$. First, we solve the deterministic case where the date of the shock $t_{a}$ is known, and second, we solve the stochastic case where $t_{a}$, is a random variable that follows an exponential distribution.

\footnotetext{
${ }^{8}$ The maximum pumping cost is the pumping cost from the deepest point of the aquifer to the surface.
} 


\subsection{The deterministic case}

We assume that there is a decrease in the recharge rate from $r_{1}$ to $r_{2}$ at a known date $t_{a}$. We are interested in the optimal path of extraction in the event this "dry period" occurs. The problem of the social planner is now :

$$
\max _{g(\cdot)} \int_{0}^{\infty} F(G, g) \quad \mathrm{e}^{-\rho \mathrm{t}} \mathrm{dt},
$$

where

$$
\begin{gathered}
F(G, g)=\frac{a}{b} g-\frac{1}{2 b} g^{2}-(z-c G) g, \\
\dot{G}=\left\{\begin{array}{llr}
-(1-\alpha) g+r_{1} & \text { if } & t \leq t_{a} \\
-(1-\alpha) g+r_{2} & \text { if } & t>t_{a},
\end{array}\right. \\
G(0)=G_{0}, t_{a} \quad \text { given, } \quad r_{1}>r_{2}, \\
g \geq 0 \quad G \geq 0 .
\end{gathered}
$$

Indeed, the main problem is to model the fact that the availability of water for irrigation decreases from $t_{a}$ on. This can happen when there is an estimated decrease in mean precipitation or because of exceptional extraction of water for other uses from $t_{a}$ on. In theory, these ideas are equivalent and we can describe them both as a decrease in the recharge rate ${ }^{9}$.

Now, we turn to the resolution of the problem. We can solve it in two steps. First, we find $\phi\left(t a, G_{t a}\right)$, the scrap value function that represents the maximization between $t_{a}$ and $\infty$, that is the solution of the problem:

$$
\begin{gathered}
\max _{g(.)} \int_{t_{a}}^{\infty}\left(\frac{a}{b} g-\frac{1}{2 b} g^{2}-(z-c G) g\right) \mathrm{e}^{-\rho\left(\mathrm{t}-\mathrm{t}_{\mathrm{a}}\right)} \mathrm{dt} \\
\dot{G}=-(1-\alpha) g+r_{2}, \\
G\left(t_{a}\right)=G_{t_{a}} \quad \text { unknown. }
\end{gathered}
$$

Subsequently, the second step of the problem is to find g that maximizes,

$$
\int_{0}^{t_{a}}\left(\frac{a}{b} g-\frac{1}{2 b} g^{2}-(z-c G) g\right) \mathrm{e}^{-\rho \mathrm{t}} \mathrm{dt}+\mathrm{e}^{-\rho \mathrm{t}_{\mathrm{a}}} \phi\left(\mathrm{t}_{\mathrm{a}}, \mathrm{G}_{\mathrm{ta}}\right) .
$$

\footnotetext{
${ }^{9}$ Consider a specific extraction of value $\mathrm{A}$, from the date $t_{a}$ on, caused by a need for other uses (water consumption, industrial use, etc...). Assume there is a return flow coefficient, $\beta(0 \leq \beta \neq \alpha)$, for this specific extraction, then this problem is equivalent to the main problem of the decrease in the recharge rate, if $r_{2}=r-(1-\beta) A=r_{1}-(1-\beta) A \Longrightarrow r_{1}-r_{2}=(1-\beta) A$.
} 


$$
\begin{aligned}
& \dot{G}=-(1-\alpha) g+r_{1} . \\
& G(0)=G_{0} \quad \text { known. }
\end{aligned}
$$

The full resolution of this modified extraction problem is given in the Appendix (A.2).

Now, we present some theoretical results proved by studying analytical solutions of the previous problems.

Let $g_{r}^{*}(t)$ (and $G_{r}^{*}(t)$ ) be optimal extractions and the stock for the deterministic shock when there is a decrease in the recharge rate from $r_{1}$ to $\mathrm{r}$ at $t_{a}$, with $r_{1} \geq r \geq 0^{10}$;

Proposition 2.1 $G_{r}^{*}(\infty)$ and $g_{r}^{*}(\infty)$ are increasing monotonic functions of $r$.

\section{Proof :}

As we can see in appendices A.2, the steady state of the stock and extractions of the deterministic problem are given respectively by equations (33) and (31), when $r=r_{2}$. We observe that the derivatives of $G_{r}^{*}(\infty)$ and $g_{r}^{*}(\infty)$ with respect to $\mathrm{r}$ are positive.

According to proposition 2.1, the higher the value of the determinitic shock (i.e. the smaller the value of $r$ ), the lower the steady state of the stock and the lower the extractions in the modified problem. Indeed, when a shock occurs (i.e. $r=r_{2}<r_{1}$ ) the optimal level of the resource drops in the long run and the resource is less intensively exploited.

Proposition $2.2 G_{r}^{*}\left(t_{a}\right)$ is an increasing monotonic function of $r$.

Proposition 2.3 $g_{r}^{*}(0)$ is a decreasing monotonic function of $r$.

Proposition $2.4 g_{r}^{*}\left(t_{a}\right)$ is a decreasing monotonic function of $r$.

Proofs are available in appendices A.4.1, A.4.2, and A.4.3 respectively.

Proposition $2.5 G_{r}^{*}(\infty)$ and $g_{r}^{*}(\infty)$ are constant as functions of $t_{a}$.

Proof We seek to prove that $\frac{\delta G_{r}^{*}(\infty)}{\delta t_{a}}=0$ and $\frac{\delta g_{r}^{*}(\infty)}{\delta t_{a}}=0$. Clearly, this follows from equations (33) and (31).

\footnotetext{
${ }^{10}$ Logically, when $r=r_{1}, g_{r}^{*}(t)$ represents the original problem in section 2.
} 
Propositions 2.2, 2.3, 2.4 state that the higher the value of the shock (i.e. the smaller the value of $r$ ), the lower the level of the resource at $t_{a}$ and the higher the extractions in $t=0$ and $t=t_{a}$. However, proposition 2.5 shows that in the long run (the steady state), optimal stock and extraction behavior do not depend on the date of occurrence of the shock $\left(t_{a}\right)$.

\subsection{The stochastic case}

Now, the date of occurrence of the shock $\left(t_{a}\right)$ is a random variable ${ }^{11}$. Let $f_{T}(t)$ be the density function, $\psi_{T}(t)=\int_{0}^{t} f_{T}(x) d x$, the distribution function, and $\Omega_{T}(t)=1-\psi_{T}(t)$, the survival function of $\mathrm{T}$.

The problem of the social planner is now to maximize the expected value of the social welfare, that is the expected value of farmers' total income,

$$
\begin{gathered}
\max _{g(.)} E_{T}\left(\int_{0}^{\infty} \mathrm{e}^{-\rho \mathrm{t}} \mathrm{F}(\mathrm{G}, \mathrm{g}) \quad \mathrm{dt}\right) \\
\dot{G}=\left\{\begin{array}{lll}
-(1-\alpha) g+r_{1} & \text { if } & t \leq T \\
-(1-\alpha) g+r_{2} & \text { if } & t>T
\end{array}\right. \\
G(0)=G_{0} \quad \text { given, } \\
g \geq 0 \quad G \geq 0 .
\end{gathered}
$$

with the profit function $F(G, g)$, as in the previous problem,

$$
F(G, g)=\frac{a}{b} g-\frac{1}{2 b} g^{2}-(z-c G) g .
$$

Following the procedure used in Dasgupta and Heal (see [5]), let $\phi(G(t))$ be the scrap value function,

$$
\phi(G(T))=\max _{g(t)} \int_{T}^{\infty} \mathrm{e}^{-\rho(\mathrm{t}-\mathrm{T})} \mathrm{F}(\mathrm{G}(\mathrm{t}), \mathrm{g}(\mathrm{t})) \mathrm{dt} .
$$

corresponding to the maximisation of total social welfare, taking into account the following dynamics of the aquifer:

$$
\dot{G}=-(1-\alpha) g+r_{2} .
$$

The maximisation function (9) is equal to

\footnotetext{
${ }^{11}$ In what follows, we denote $t_{a}=T$ for the sake of simplicity.
} 


$$
\max _{g(.)} \int_{0}^{\infty} f_{T}(T)\left[\int_{0}^{T} \mathrm{e}^{-\rho \mathrm{t}} \mathrm{F}(\mathrm{G}(\mathrm{t}), \mathrm{g}(\mathrm{t})) \mathrm{dt}+\mathrm{e}^{-\rho \mathrm{T}} \phi(\mathrm{G}(\mathrm{T}))\right] d T
$$

So:

$$
\max _{g(.)} \int_{0}^{\infty} f_{T}(T)\left[\int_{0}^{T} \mathrm{e}^{-\rho \mathrm{t}} \mathrm{F}(\mathrm{G}(\mathrm{t}), \mathrm{g}(\mathrm{t})) \mathrm{dt}\right] \quad d T+\int_{0}^{\infty} \mathrm{e}^{-\rho \mathrm{T}} \mathrm{f}_{\mathrm{T}}(\mathrm{T}) \phi(\mathrm{G}(\mathrm{T})) \quad \mathrm{dT} .
$$

Solving by parts the first integral in the previous function (12), we find that:

$$
\int_{0}^{\infty} f_{T}(T)\left[\int_{0}^{T} \mathrm{e}^{-\rho \mathrm{t}} \mathrm{F}(\mathrm{G}(\mathrm{t}), \mathrm{g}(\mathrm{t})) \mathrm{dt}\right] \quad d T=\int_{0}^{\infty} \mathrm{e}^{-\rho \mathrm{T}} \Omega_{\mathrm{T}}(\mathrm{T}) \mathrm{F}(\mathrm{G}(\mathrm{T}), \mathrm{g}(\mathrm{T})) \quad \mathrm{dT}
$$

The maximisation function (12) and hence problem (9) can be written as:

$$
\begin{gathered}
\max _{g(.)} \int_{0}^{\infty} \mathrm{e}^{-\rho \mathrm{t}}\left[\Omega_{\mathrm{T}}(\mathrm{t}) \mathrm{F}(\mathrm{G}(\mathrm{t}), \mathrm{g}(\mathrm{t}))+\mathrm{f}_{\mathrm{T}}(\mathrm{t}) \phi(\mathrm{G}(\mathrm{t}))\right] \quad \mathrm{dt} \\
\dot{G}=-(1-\alpha) g+r_{1} .
\end{gathered}
$$

Next, we seek to estimate the distribution of the random shock. We choose an exponential distribution to estimate the date of occurrence of the shock because it corresponds to a case of constant hazard (i.e. the conditional density for immediate occurrence is constant).

T now follows an exponential distribution, where $f_{T}(t)$, is the density function:

$$
f_{T}(t)=\theta \mathrm{e}^{-\theta \mathrm{t}}
$$

$\Omega_{T}(t)$ is the survival function,

$$
\Omega_{T}(t)=\mathrm{e}^{-\theta \mathrm{t}}
$$

and then, $\mathrm{h}(\mathrm{t})$, the conditional density for immediate occurrence,

$$
h(t)=\frac{f_{T}(t)}{\Omega_{T}(t)}=\theta
$$

The problem of the social planner becomes ${ }^{12}$ :

$$
\max _{g(.)} \int_{0}^{\infty} \mathrm{e}^{-(\rho+\theta) \mathrm{t}}[\mathrm{F}(\mathrm{G}, \mathrm{g})+\theta \phi(\mathrm{G})] \mathrm{dt}
$$

\footnotetext{
${ }^{12}$ We remember that the value of the change in the recharge rate, $r_{2}$, enters the stochastic problem via the scrap value function $\phi(G)$.
} 


$$
\begin{gathered}
\dot{G}=-(1-\alpha) g+r_{1} \\
G(0)=G_{0} \quad \text { given, } \\
g \geq 0 \quad G \geq 0 .
\end{gathered}
$$

The full resolution of this modified extraction problem is given in Appendix A.3.

Let $G_{r S}^{*}(t)$, (and $\left.g_{r S}^{*}(t)\right)$ be optimal solutions of stock and extractions for the stochastic problem when there is a decrease on the recharge rate from $r_{1}$ to $\mathrm{r}$ at $t_{a}$, with $r_{1} \geq r \geq 0$;

Proposition $2.6 G_{r^{S}}^{*}(\infty)$ (and $g_{r^{S}}^{*}(\infty)$ ) are increasing monotonic (and constant) functions of $r$.

Proposition $2.7 G_{r^{S}}^{*}(\infty)$ (and $g_{r S}^{*}(\infty)$ ) are decreasing monotonic (and constant) functions of $\theta$.

Proofs are available in appendices A.4.4 and A.4.5 respectively.

Propositions 2.6 and 2.7 state that the higher the value of the shock (i.e. the smaller the value of $r$ ) and, respectively, the smaller the value of $\theta$, the lower the level of the resource in the long run, while the water pumping rate stays constant.

\subsection{Deterministic vs. stochastic case}

One of the objectives of this paper is to compare optimal adaptation behavior when there is an increase in uncertainty about the date the shock occurs. We have now analytical solutions for the deterministic problem (in section 2.1) and the stochastic problem (in section 2.2). A comparison between situations in which the occurrence time is known or stochastic is meaningful only if the known time $\left(t_{a}\right)$ equals the expected value of the uncertain time $(\mathrm{T})$, that is,

$$
t_{a}=E_{T}(t)=\int_{0}^{\infty} t \theta \mathrm{e}^{-\theta \mathrm{t}} \mathrm{dt} .
$$

Solving by parts the integral in equation (18), we obtain,

$$
t_{a}=\frac{1}{\theta}
$$

Now, we present some theoretical results proved by studying the analytical solutions of the previous problems.

We assume there is a decrease on the recharge rate from $r_{1}$ to $r_{2}$ at $t_{a}$. Then, 
- $G_{r_{2}}^{*}(t)$, (and $\left.g_{r_{2}}^{*}(t)\right)$ are optimal solutions of stock and extractions for the deterministic problem, when $r=r_{2}$;

- $G_{r_{2}^{S}}^{*}(t)$, (and $g_{r_{2}^{S}}^{*}(t)$ ) are optimal solutions of stock and extractions for the stochastic problem when $r=r_{2}$;

Proposition $2.8 G_{r_{2}}^{*}(\infty)<G_{r_{2}^{S}}^{*}(\infty)$ and $\left.g_{r_{2}}^{*}(\infty)<g_{r_{2}^{S}}^{*}(\infty)\right)$.

Proof As we show in equation (33),

$$
G_{r_{2}}^{*}(\infty)=\frac{r_{2}}{(1-\alpha) c b}+\frac{r_{2}}{\rho}-\frac{a}{b c}+\frac{z}{c} .
$$

From equation (55), we know that,

$$
G_{r_{2}^{S}}^{*}(\infty)=\frac{(a-z b)(1-\alpha)(\rho+\theta)-r_{1}(\rho+\theta)-c b(1-\alpha) r_{1}-b(1-\alpha)^{2} \theta \tau}{b(1-\alpha)(-c \rho-c \theta+2 \theta v(1-\alpha))} .
$$

Then, substituing the values of $\tau$ and $v$ (equations (38), (39)), we prove that,

$$
G_{r_{2}}^{*}(\infty)-G_{r_{2}^{S}}^{*}(\infty)=\frac{\left(r_{2}-r_{1}\right) E 1}{E 2},
$$

with,

$$
\begin{gathered}
E 1=(\rho+\eta+4 c b(1-\alpha))(c b(1-\alpha+\rho+\theta)), \quad \text { and } \\
E 2=c b(1-\alpha)\left(\rho \eta+\rho^{2}+4 c b(1-\alpha) \rho+2 \theta \eta\right),
\end{gathered}
$$

with $\eta>0$ (see equation (40)).

By assumption, $\left(r_{2}-r_{1}\right)<0$, and all the parameters of the problem are positive. Thus, $E 1, E 2>0$, and, $G_{r_{2}}^{*}(\infty)-G_{r_{2}^{S}}^{*}(\infty)<0$, as required.

It remains to be demonstrated that $g_{r_{2}}^{*}(\infty)<g_{r_{2}^{S}}^{*}(\infty)$. From equations (31) and (53),

$$
g_{r_{2}^{S}}^{*}(\infty)=\frac{r_{1}}{(1-\alpha)}>\frac{r_{2}}{(1-\alpha)}=g_{r_{2}}^{*}(\infty)
$$

because $r_{1}>r_{2}$. 
Proposition 2.8 proves that in the long run, the resource drops to a lower level (and respectively, extractions are more conservative), in the case of certainty about the date of the shock than in the case of uncertainty. In the stochastic problem, long-run resource stocks and long-run extractions do depend on the initial recharge rate $r_{1}$, which is greater than recharge rate after the shock, $r_{2}$. In consequence, steady-state stocks and extractions are greater than in the deterministic case.

\section{Numerical application}

In this section, we apply our problem to the Western la Mancha aquifer. We use real parameter values from several sources (e.g. Esteban and Albiac (2011) [8], Esteban and Dinar (2012) [9]). Note that we analyze the problem in terms of the stock level of the aquifer (in volume), i.e, by multiplying the current water table, the area of the aquifer, A, and the storativity coefficient, S. The parameter values used are listed in Table $1^{13}$.

The Western la Mancha aquifer is located in the South of Spain. The development of intensive irrigated agriculture in recent decades has led to an increase in groundwater extraction in the area and, as a consequence, a decrease in the water table. It is estimated that 3000 million cubic meters have been abstracted from the aquifer over the past three decades (e.g. López-Gunn [12]). This problem has caused significant damage to aquatic ecosystems and also affects human uses downstream. Moreover, the Western la Mancha aquifer has also suffered from inefficient management regimes, (for details see [8]). During a dry period, it is clear that this problem may become more acute.

\subsection{Optimal solutions for the deterministic case}

We first give a numerical example of the deterministic case. Figure 1 depicts optimal solutions of stock $G^{*}(t)$ (on the left) and water pumping rate $g^{*}(t)$ (on the right), for the original problem described in section 2 (in green) and for different values of a deterministic shock occurring in the $20^{t h}$ year of resource use, (i.e. $t_{a}=20$ ). More specifically, we simulate a decrease in the recharge from an initial level of $r_{1}=360$ to a level of $r_{2}=330$ (in red), 300 (in blue) and 290 (in black) million cubic meters per year $\left(\mathrm{Mm}^{3} / \mathrm{yr}\right) .{ }^{14}$

In the deterministic case, long-run resource stocks, $G^{*}(\infty)$, are equal to $78397 \mathrm{Mm}^{3}$ and long-run extractions, $g^{*}(\infty)$, are equal to $450 \mathrm{Mm}^{3} / \mathrm{yr}^{15}$ We note that, with a de-

\footnotetext{
${ }^{13}$ For details, the groundwater stock is computed by multiplying the height of the aquifer by the aquifer area and the storativity coefficient: $G_{0}=H_{0} * A * S=640 * 5500 * 0.023$. Coefficients of pumping costs are defined as follows: $\mathrm{z}$ is equal to maximum pumping cost, that is the pumping cost from the deepest point of the aquifer to the surface and is computed by multiplying the surface elevation by the unit pumping costs i.e, $S_{L} * c^{\prime}$ (with $c^{\prime}$ equal to 400 Euros $/ \mathrm{Mm}^{3} . \mathrm{m}$ ); c is converted into Euros/(Million Cubic Meters) ${ }^{2}$ by dividing $c^{\prime}$ by $\mathrm{A}^{*} \mathrm{~S}$.

${ }^{14}$ We chose $t_{a}=20$ years and the different values of the shock following observations made in the area in the 1990s, (see Esteban and Dinar [9] for details).

${ }^{15}$ According to López-Gunn [12], renewable extractions are estimated to amount to $300 \mathrm{Mm}^{3} / \mathrm{yr}$.
} 


\begin{tabular}{cllr} 
Parameters & Description & Units & Value \\
\hline $\mathrm{b}$ & Water demand slope & (Million Cubic Meters/Year) ${ }^{2}$ Euros $^{-1}$ & 0.097 \\
$\mathrm{a}$ & Water demand intercept & Million Cubic Meters/Year & 4403.3 \\
$\mathrm{z}$ & Pumping costs intercept & Euros/Million Cubic Meters & 266000 \\
$\mathrm{c}$ & Pumping costs slope & Euros/(Million Cubic Meters) & 3.162 \\
$\mathrm{r}$ & Natural recharge & Million Cubic Meters/Year & 360 \\
$G_{0}$ & Stock level (in volume) & Million Cubic Meters & 80960 \\
$H_{0}$ & Current water table & Meters & 640 \\
$S_{L}$ & Surface elevation & Meters & 665 \\
$\mathrm{~A}$ & Aquifer area & Square Kilometers & 5500 \\
$\mathrm{~S}$ & Storativity coefficient & unitless & 0.023 \\
$\rho$ & Social discount rate & Year & \\
$\alpha$ & Return flow coefficient & unitless & 0.05 \\
\end{tabular}

Table 1: Values of parameters of the Western la Mancha aquifer.
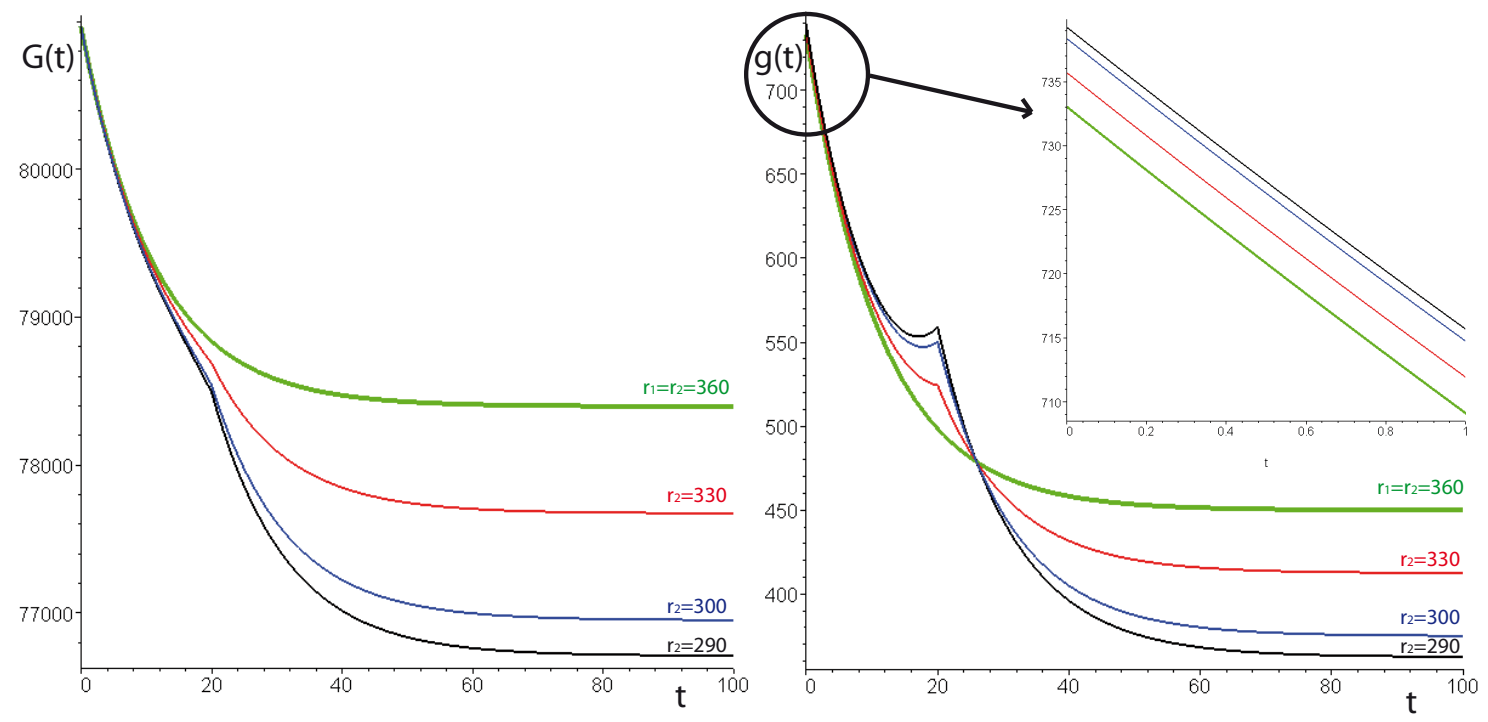

Figure 1: $G^{*}(t)$ in million cubic meters (left-hand side) and $g^{*}(t)$ (right-hand side) in million cubic meters per year for different values of $r_{2}$ and ta $=20$ years. Upper right-hand corner: zoom on $g^{*}(t)$ between $t=0$ and $t=1$ years.

crease in $r_{2}$, the steady state resource drops to a lower level and extractions are more conservative in the long run. For example, for a shock of $70 \mathrm{Mm}^{3} / \mathrm{yr}$ the level of the resource decreases by $1685 \mathrm{Mm}^{3}$ and extractions decrease by $87 \mathrm{Mm}^{3} / \mathrm{yr}$. This illustrates the above proposition 2.1, proved in section 2.1. Second, at the time the shock occurs the resource is more exploited and extractions are greater the more intense the shock, i.e. 
$G^{*}\left(t_{a}\right)$ decreases and $g^{*}\left(t_{a}\right)$ increases with a decrease in $r_{2}$. For example, for a shock of $70 \mathrm{Mm}^{3} / \mathrm{yr}$, extractions increase by about $61 \mathrm{Mm}^{3} / \mathrm{yr}$. This illustrates propositions 2.2 and 2.4. We can also confirm that the resource is more exploited at the beginning of the exercise the higher the value of the shock: $g^{*}(0)$ increases from 733 to $739 \mathrm{Mm}^{3} / \mathrm{yr}$, when $r_{2}$ decreases by $70 \mathrm{Mm}^{3} / \mathrm{yr}$. This result illustrates the above proposition $2.3 .{ }^{16}$

Next, we study the impact of the occurrence date of the shock $\left(t_{a}\right)$ on optimal behavior. Figure 2 depicts optimal solutions of stock $G^{*}(t)$ (on the left) and water pumping rate $g^{*}(t)$ (on the right) for the original problem described in section 2 (in green) and for the problem with a shock of $70 \mathrm{Mm}^{3} / \mathrm{yr}$ at different values of $t_{a}$. First, we note that the long run (steady state) stock and water pumping rate are constant. Hence, the date of occurrence of the shock has no impact on the steady state values of $G^{*}(t)$ and $g^{*}(t)$. This is proved theorically in proposition 2.5. However, in the short run, the value of $g^{*}(t)$ (in $\mathrm{t}=0$ and $\mathrm{t}=t_{a}$ ) decreases with an increase in $t_{a}$. For example, $g^{*}(0)$ decreases by about 43 $\mathrm{Mm}^{3} / \mathrm{yr}$ when $t_{a}$ increases from $t_{a}=5$ to $t_{a}=20$. In the same way, $g^{*}\left(t_{a}\right)$ decreases by about $146 \mathrm{Mm}^{3} / \mathrm{yr}$ when $t_{a}$ increases from $t_{a}=5$ to $t_{a}=20$. Then, we calculate total extractions before $t_{a}$ and we obtain that they increase by about $8398 \mathrm{Mm}^{3} / \mathrm{yr}$, when $t_{a}$ increases from $t_{a}=5$ to $t_{a}=20$, and as a consequence, we can see that the resource reaches a lower level at $t_{a}$ the later the shock occurs. In sum, we can say that the date of occurrence of the shock has an impact on the short run values of $G^{*}(t)$ and $g^{*}(t)$.

In figures 1 and 2, we also observe a surprising behavior concerning the optimal water pumping rate. Optimal extractions are non-monotonic in the short run: there is first a decrease in extraction and then an increase just before the shock occurs. This behavior is more pronounced the greater the shock (see Figure 1) and the later it takes place (see Figure 2). In order to better understand this result, we compute the difference between the deterministic shock and the simple problem, as depicted in figure 3 , for different values of $r_{2}$ (left-hand side) and $t_{a}$ (right-hand side). First, the higher the value of the shock, the higher the amount of water pumping and the quicker the increase in extractions between $t=0$ and $t=t_{a}$ (as illustrated on the left-hand side). This result may be explained by the fact that the water agency increases short-run extractions when the shock is more intense in order to accumulate gains and compensate for future losses. Next, the later the shock occurs, the higher the overall extraction and the slower the increase in extractions before the occurence of the shock (as illustrated on the right-hand side). The latter result can be explained by the fact that the water agency has more time to better adapt to the shock.

Next, in Tables 2 and 3, we calculate the social welfare, as defined in equation (4), corresponding to the simulations carried out in the previous figures 1 and 2. In Table 2 we show that social welfare increases in the first period (before $t_{a}$, column 1 ) and decreases in

\footnotetext{
${ }^{16}$ We can compare the estimated drop of $3000 \mathrm{Mm}^{3}$ over the last 30 years reported by López-Gunn to our values, where $\mathrm{G}(0)=80960 \mathrm{Mm}^{3}$ and $G\left(t_{a}=20\right)$ in $t=30$ is equal to $77608 \mathrm{Mm}^{3}$.
} 
Author-produced version of the article published in Journal of Economic Dynamics and Control, 2014, N40, p. 134-153. The original publication is available at http://www.sciencedirect.com/science/article/pii/S0165188914000141

Doi: 10.1016/j.jedc.2014.01.005
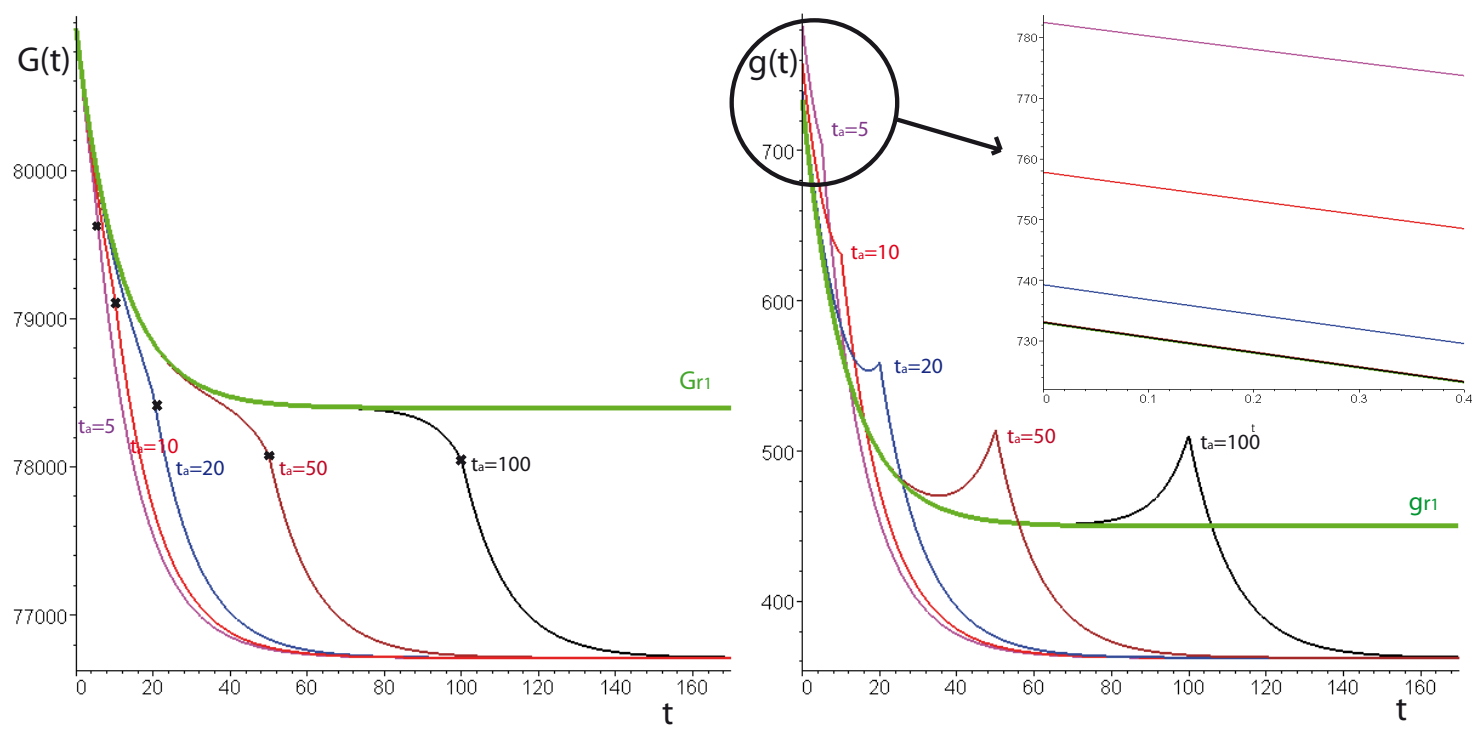

Figure 2: $G^{*}(t)$ in million cubic meters (left-hand side) and $g^{*}(t)$ (right-hand side) in million cubic meters per year for different values of $t_{a}$ and $r_{2}=290$ million cubic meters per year. Upper right-hand corner: zoom on $g^{*}(t)$ between $t=0$ and $t=0.4$ years.
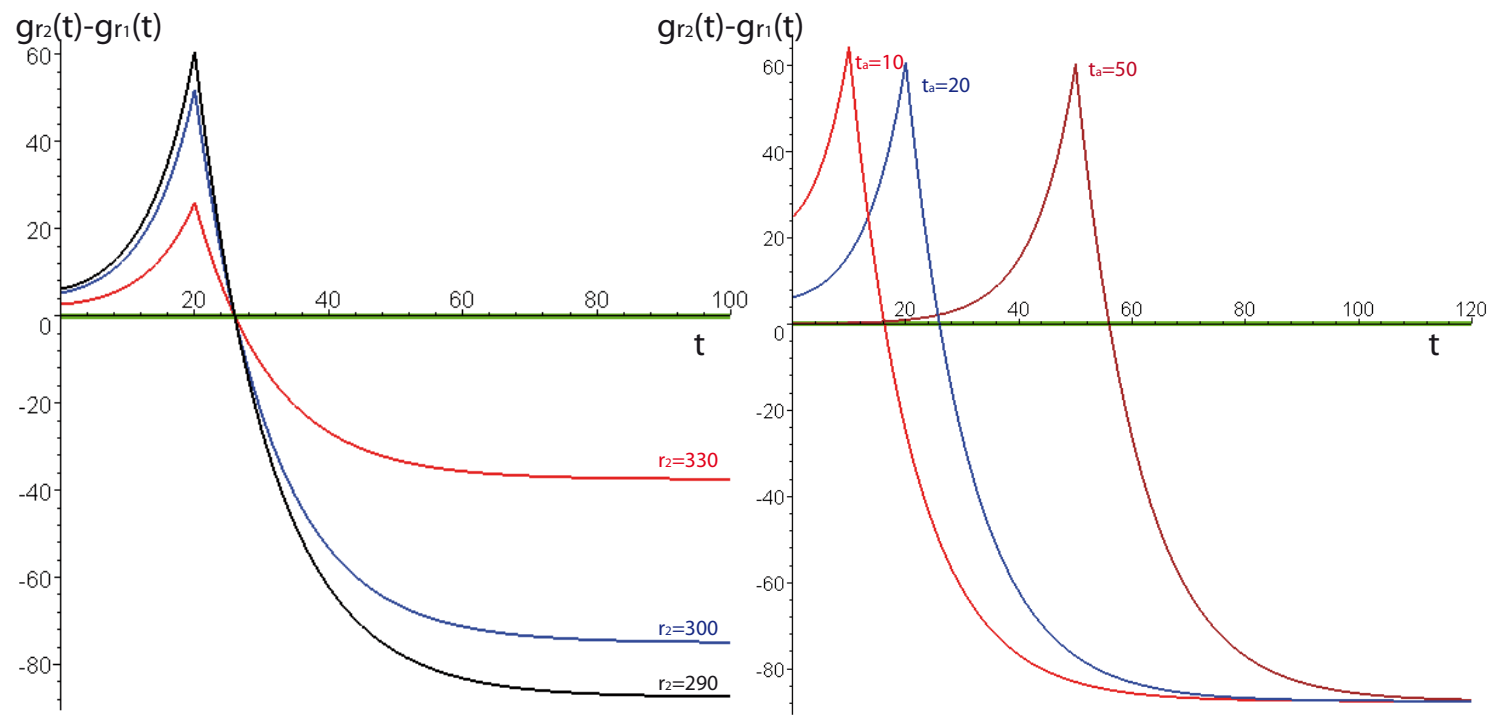

Figure 3: Difference between extractions with and without shock in $t_{a}=20$ years for different values of $r_{2}$ (left-hand side) and with $r_{2}=290$ million cubic meters per year at different dates (right-hand side). 


\begin{tabular}{|c|c|c|c|c|c|}
\hline & $\begin{array}{c}(1) \\
{\left[0, t_{a}\right]}\end{array}$ & $\begin{array}{c}(2) \\
{\left[t_{a}, \infty\right]}\end{array}$ & $\begin{array}{c}(3) \\
{[0, \infty]}\end{array}$ & $\left(\right.$ in $\left.^{\frac{1}{3}} \%\right)$ & $\left(\right.$ in $\left.^{\frac{2}{3}} \%\right)$ \\
\hline$r_{1}=r_{2}=360$ & 219311 & 87757 & 307068 & 71 & 29 \\
\hline$r_{2}=330$ & 220893 & 80009 & 300902 & 73 & 27 \\
\hline$r_{2}=300$ & 222424 & 72720 & 295144 & 75 & 25 \\
\hline$r_{2}=290$ & 222924 & 70392 & 293315 & 76 & 24 \\
\hline
\end{tabular}

Table 2: Social welfare for a shock at $t_{a}=20$ years in thousands of Euros (values rounded) for different values of $r_{2}$ and different time-periods.

the second period (after $t_{a}$, column 2) with an increase in the value of the shock. Logically, the total social welfare (column 3) decreases with an increase in the value of the shock. For example, when the value of the shock increases by $70 \mathrm{Mm}^{3} / \mathrm{yr}$, total welfare decreases by about 14 million Euros. The percentage gain in the first period (column 4 ) is the higher the greater the shock due to the compensation seeking behavior described above. Logically, the percentage gain in the second period (column 5) is lower the greater the shock. Next, in table 3, we show that social welfare increases the later the shock occurs. We can dstinguish two phenomena: ${ }^{17}$ first, the damage occurring later in time is reduced due to discounting. Second, eliminating the effect of discounting, the loss in social welfare is greater when the shock occurs in early stages than when it occurs at later stages. ${ }^{18}$ The latter may be due to the fact that the water agency has more time to better adapt to the shock, as described in the previous paragraph.

\begin{tabular}{lccccccc} 
& $\mathbf{t}_{\mathbf{a}}=\mathbf{5}$ & $\mathbf{t}_{\mathbf{a}}=\mathbf{1 0}$ & $\mathbf{t}_{\mathbf{a}}=\mathbf{2 0}$ & $\mathbf{t}_{\mathbf{a}}=\mathbf{5 0}$ & $\mathbf{t}_{\mathbf{a}}=\mathbf{1 0 0}$ & $\mathbf{t}_{\mathbf{a}}=\mathbf{1 5 0}$ & $\mathbf{t}_{\mathbf{a}}=\mathbf{2 0 0}$ \\
\hline$r_{2}=359$ & 306602 & 306711 & 306856 & 307021 & 307064 & 307067 & 307068 \\
$r_{2}=330$ & 293489 & 296694 & 300902 & 305710 & 306957 & 307059 & 307067 \\
$r_{2}=300$ & 280754 & 286987 & 295144 & 304444 & 306853 & 307050 & 307066 \\
$r_{2}=290$ & 276696 & 283900 & 293315 & 304042 & 306820 & 307047 & 307066 \\
$r_{2}=150$ & 229727 & 248467 & 272469 & 299478 & 306446 & 307017 & 307064 \\
\hline
\end{tabular}

Table 3: Social welfare (in thousands of Euros) for different values of $r_{2}$ and $t_{a}$.

As a result, the theoretical and numerical solutions clearly show that the greater the shock, the higher both extractions and social welfare in the first period (before the occurrence of the shock). The water agency accumulates gains to compensate for losses incurred during the second period. In the second period, the quantity of water extracted and social welfare are reduced. As a consequence, in the long run, the greater the shock the lower

\footnotetext{
${ }^{17}$ We would like to thank an anonymous referee for this interpretation.

${ }^{18}$ Indeed, the value of a shock corresponding to the difference between $r_{2}=359$ and $r_{2}=150$ is equal to 4000 Euros in $t=200$. The value of thes same shock occurring in $t=5$ but being evaluated at $t=200$ is equal to 4481 Euros.
} 
both extractions and social welfare. Moreover, the greater the shock, the lower the level of the long-term resource stock, because of the decrease of the recharge rate. Total social welfare decreases the higher the value of the shock, which shows that the water agency should expend more effort to adapt to the shock. The numerical solutions also suggest that the later the shock occurs, the lower the speed of adaptation for extractions but the greater the total social welfare. This means that the water agency has more time to better adapt to the shock.

\subsection{Optimal solutions for the stochastic case}

We now construct a numerical example for the stochastic case: $t_{a}$, the date of the shock, is a random variable which follows an exponential distribution with a known parameter $\theta$, (see section 2.2). Indeed, the hazard function is a constant function (equal to $\theta$ ), which corresponds to the conditional probability of immediate occurrence (or the probability of occurrence at $\mathrm{t}$ given that the shock has not yet occurred).

In Figure 4, we see the optimal solutions of stock $G^{*}(t)$ and extractions $g^{*}(t)$ for the initial problem described in section 2 (in green) and for different values of the stochastic shock, namely $r_{2}=330$ (in red), 290 (in magenta) and 150 (in black) $\mathrm{Mm}^{3} / \mathrm{yr}$, when $\theta=0.05$. To illustrate, the probability for a shock occurring before the end of the fifth year is $22 \%$. In the right-hand corner of the figure, a zoom shows optimal extraction between $\mathrm{t}=0$ and $\mathrm{t}=2$ years.

First, we observe that, as previously, the steady state of the stock is lower when the shock is greater. For example when $r_{2}$ decreases by $70 \mathrm{Mm}^{3} / \mathrm{yr}$, the stock decreases by around $237 \mathrm{Mm}^{3}$. However, water pumping remains the same in the long run. This is proved theorically in proposition 2.6. Also, at $t=0$, the amount of water extracted is greater, the greater the shock. This is depicted in the right-hand corner of the figure.

Second, figure 5 depicts optimal solutions for different values of $\theta$, the parameter of the distribution function, for a shock of $70 \mathrm{Mm}^{3} / \mathrm{yr}$. When the conditional probability of immediate occurrence decreases, there is a decrease in the amount of water extracted. For example, when $\theta$ decreases from $\theta=0.2$ to $\theta=0.05, g^{*}(t)$ decreases by approximately $32 \mathrm{Mm}^{3}$ at $t=0$. Indeed, $\theta$ is a measure of risk, and when this risk decreases, optimal extraction behavior is less intensive in the short run. This is depicted in the right-hand side of Figure 5. When the conditional probability of immediate occurrence decreases, optimal extraction behavior being less intensive, resource use is more prudent, and the level of the resource increases in the long run. This is shown in the left-hand side of Figure 5. Logically, when $\theta$ increases, the level of the resource drops in the long run. This is an illustration of proposition 2.7. 

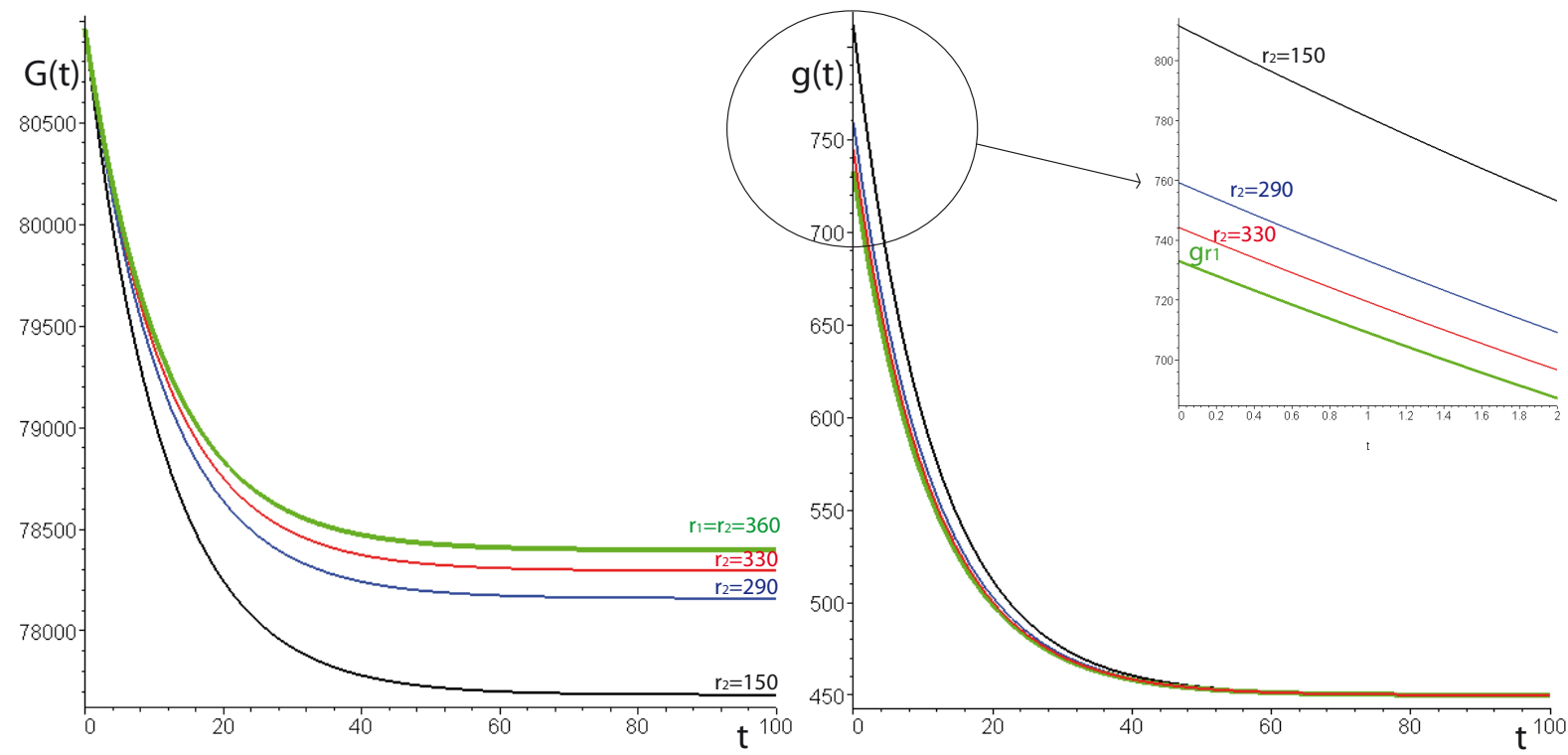

Figure 4: $G^{*}(t)$ in million cubic meters (left-hand side) and $g^{*}(t)$ in million cubic meters per year (right-hand side) for different values of $r_{2}$ and $\theta=0.05$. Upper right-hand corner: zoom on $g^{*}(t)$ between $t=0$ and $t=2$ years.

Finally, we calculate the social welfare, as defined in equation (9), for different values of the conditional probability of immediate occurrence $(\theta)$ and values of the shock $\left(r_{2}\right)$. Results are shown in Table 4 . When the conditional probability of occurrence $(\theta)$ is fixed, social welfare decreases with an increase in the value of the shock (i.e. the higher $r_{2}$ ). For example, for a shock of $70 \mathrm{Mm}^{3} / \mathrm{yr}$ and $\theta=0.05$, social welfare decreases by around 19 million Euros. Moreover, when the value of the shock $\left(r_{2}\right)$ is fixed, social welfare increases the lower the "risk", as measured by $\theta$. These results are as expected.

\begin{tabular}{lccccccc} 
& $\theta=\mathbf{0 . 2}$ & $\theta=\mathbf{0 . 1}$ & $\theta=\mathbf{0 . 0 5}$ & $\theta=\mathbf{0 . 0 2}$ & $\theta=\mathbf{0 . 0 1}$ & $\theta=\mathbf{0 . 0 0 7}$ & $\theta=\mathbf{0 . 0 0 5}$ \\
\hline$r_{2}=359$ & 306585 & 306669 & 306771 & 306890 & 306970 & 306999 & 307015 \\
$r_{2}=330$ & 293003 & 295450 & 298422 & 302161 & 304214 & 305055 & 305514 \\
$r_{2}=300$ & 279786 & 284538 & 290302 & 297552 & 301532 & 303164 & 304053 \\
$r_{2}=290$ & 275568 & 281058 & 287712 & 296082 & 300677 & 302561 & 303587 \\
$r_{2}=150$ & 226416 & 240579 & 257605 & 278973 & 290715 & 295533 & 298158 \\
\hline
\end{tabular}

Table 4: Social welfare in thousands of Euros for different values of $r_{2}$ and $\theta$.

In sum, the numerical solutions show that the higher the value of the stochastic shock, the lower social welfare, although there is an increase in extractions in the short run. As 

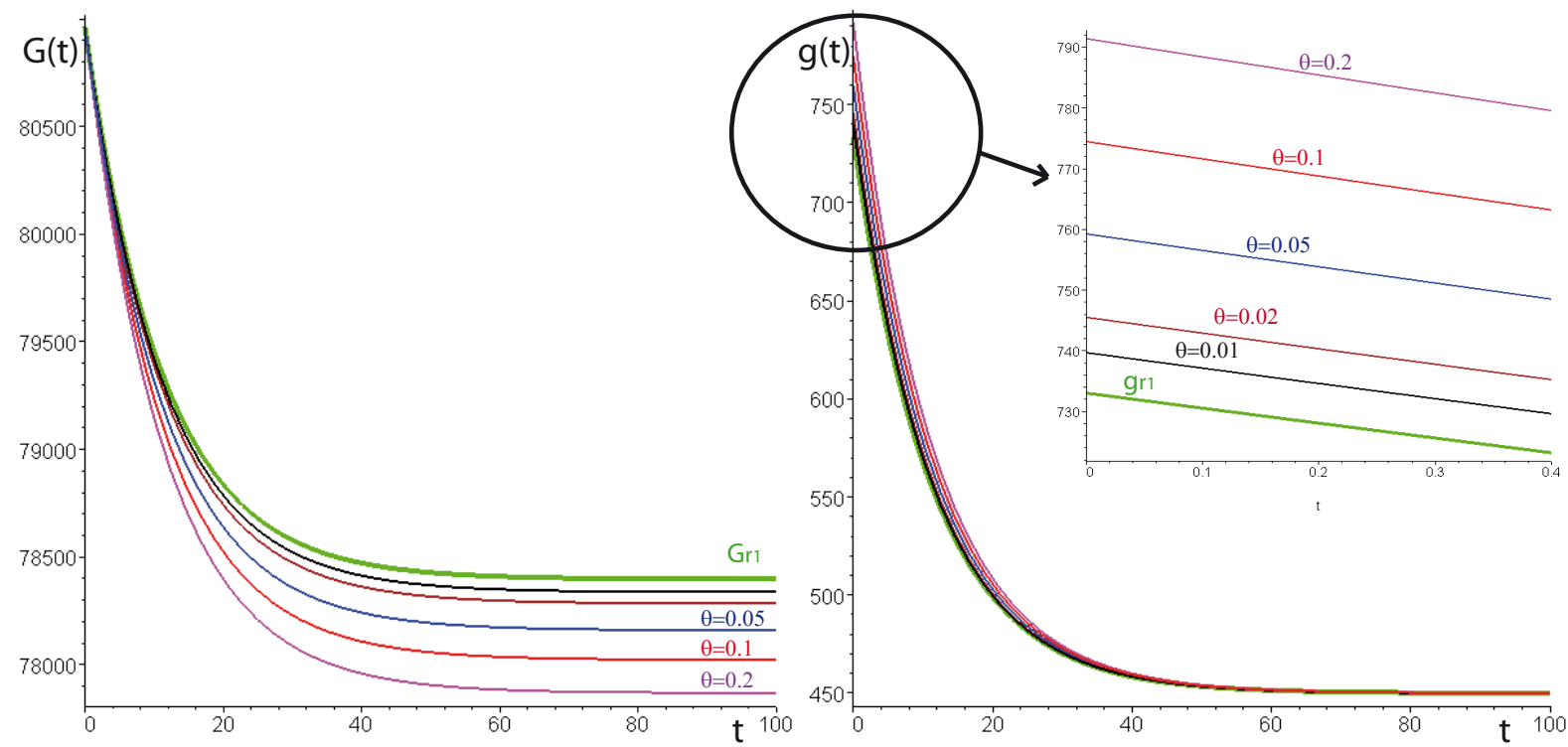

Figure 5: $G^{*}(t)$ in million cubic meters (left-hand side) and $g^{*}(t)$ in million cubic meters per year (right hand side) for different values of $\theta$ and $r_{2}=290$ million cubic meters per year. Upper right-hand corner: zoom on $g^{*}(t)$ between $t=0$ and $t=0.4$ years.

in the previous section, this result is logical because the water agency has to exert a bigger effort in order to adapt to the shock. Moreover, a lower risk of occurrence (the decrease of $\theta$ ) implies more careful extraction behaviour, a greater long-term resource level, and an increase in social welfare.

\subsection{Deterministic case vs. stochastic case}

In this section, we analyze the impact of an increase in uncertainty (concerning the occurrence date of the shock) on precautionary extraction behavior and social welfare by using numerical simulations.

In Figure 6, we compare optimal solutions of the stock $G^{*}(t)$ and extractions $g^{*}(t)$ for the initial problem described in section 2 (in green), for the deterministic shock (in blue), and for the stochastic shock (in red), when the value of the shock $\left(r_{2}=290 \mathrm{Mm}^{3} / \mathrm{yr}\right.$ ), the date of the deterministic shock $\left(t_{a}=20\right.$ years), and the conditional probability of the stochastic shock $(\theta=0.05)$ are fixed. In fact, we compare the deterministic shock and the stochastic shock such that the known date $t_{a}$ is equal to the expected value of the unknown date, $\frac{1}{\theta}$, (see section 2.3 for details).

Focusing on Figure 6, we note that the resource level (on the left-hand side) in the long 

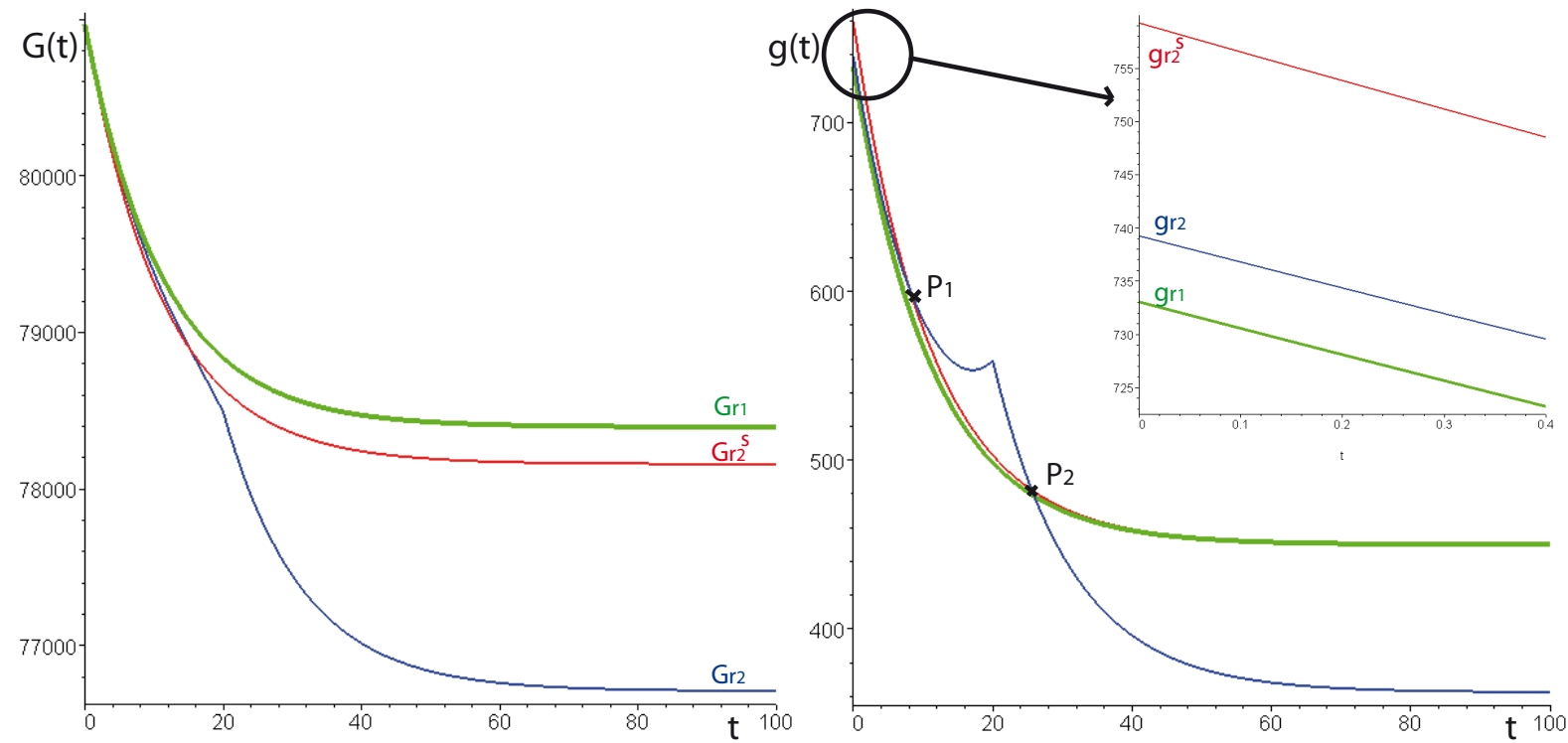

Figure 6: $G^{*}(t)$ in million cubic meters (left-hand side) and $g^{*}(t)$ in million cubic meters per year (right hand side) for the simple problem (in green), the deterministic shock (in blue) and the stochastic shock (in red), when $r_{2}=290$ million cubic meters per year. Upper right-hand corner: zoom on $g^{*}(t)$ between $t=0$ and $t=0.4$ years.

run is about $1449 \mathrm{Mm}^{3}$ smaller in the case of the deterministic shock than in the case of the stochastic shock, although extractions (on the right-hand side) in the long run are less intensive (by about $87 \mathrm{Mm}^{3}$ per year). This result illustrates proposition 2.8. In the short run, however, the inverse holds: the level of the resource is lower in the stochastic case than in the deterministic case, as depicted on the left-hand side of Figure 6. Moreover, we note an interesting behavior on the right-hand side of the figure: the optimal path of extractions for the deterministic (in blue) and the stochastic case (in red) intersect at two points $P_{1}$ (before $t_{a}$ ) and $P_{2}$ (after $t_{a}$ ). In the first period $\left[0, P_{1}\right)$, extractions are more intensive for the stochastic case, (for details, see the zoom between $\mathrm{t}=0$ and $\mathrm{t}=0.4$ in the top right-hand corner of the figure). In contrast, in the second period $\left[P_{1}, P_{2}\right)$, extractions are more intensive for the deterministic case.

Next, we compute the difference (D) in social welfare between the deterministic case and the stochastic case, (see table 5). We first observe that $\mathrm{D}$ is always positive. ${ }^{19}$ This means that the deterministic shock is less costly for society than the stochastic shock. That is, it is best to have information about the date the shock will occur. Second, we observe that the more important the value of the shock (i.e., the lower $r_{2}$ ), the more important the value of

\footnotetext{
${ }^{19}$ We only consider cases in which a shock occurs.
} 
D. That is, the more advantageous is it for the water agency to acquire information about the shock. This result is logical and corresponds to results obtained when we analyzed the two problems (the deterministic and the stochastic problem) independently. Finally, we can observe a non-monotonic relation between $t_{a}$ and $\mathrm{D}$. Indeed, the function $\mathrm{D}\left(t_{a}\right)$ first increases and then decreases from a point between $t_{a}=50$ and $t_{a}=100$ years. Delaying the shock, or equivalently decreasing the conditional probability of immediate occurrence, first makes it more and more useful for the water agency to acquire more information about the date of the shock but from a certain date the inverse holds and acquiring information is less and less useful. This result is due to the combined effect of an increase in the value of information over time and a decrease in distant values of information due to discounting. The latter effect becomes stronger than the former from $t_{a}=50$ on. ${ }^{20}$

\begin{tabular}{cccccccc} 
& $\mathbf{t}_{\mathbf{a}}=\mathbf{5}$ & $\mathbf{t}_{\mathbf{a}}=\mathbf{1 0}$ & $\mathbf{t}_{\mathbf{a}}=\mathbf{2 0}$ & $\mathbf{t}_{\mathbf{a}}=\mathbf{5 0}$ & $\mathbf{t}_{\mathbf{a}}=\mathbf{1 0 0}$ & $\mathbf{t}_{\mathbf{a}}=\mathbf{1 5 0}$ & $\mathbf{t}_{\mathbf{a}}=\mathbf{2 0 0}$ \\
& $\boldsymbol{\theta}=\mathbf{0 . 2}$ & $\theta=\mathbf{0 . 1}$ & $\theta=\mathbf{0 . 0 5}$ & $\theta=\mathbf{0 . 0 2}$ & $\theta=\mathbf{0 . 0 1}$ & $\theta=\mathbf{0 . 0 0 7}$ & $\theta=\mathbf{0 . 0 0 5}$ \\
\hline$r_{2}=359$ & 17 & 42 & 85 & 131 & 94 & 68 & 53 \\
$r_{2}=330$ & 486 & 1244 & 2480 & 3549 & 2743 & 2004 & 1553 \\
$r_{2}=300$ & 968 & 2449 & 4842 & 6892 & 5321 & 3886 & 3013 \\
$r_{2}=290$ & 1128 & 2842 & 5603 & 7960 & 6143 & 4486 & 3479 \\
$r_{2}=150$ & 3311 & 7888 & 14864 & 20505 & 15731 & 11484 & 8906 \\
\hline
\end{tabular}

Table 5: Difference between social welfare in the deterministic case and in the stochastic case in thousands of Euros for different values of $r_{2}$ and $\left(t_{a}, \theta\right)$.

For the water agency in the La Mancha basin, these results mean that it is always useful to acquire more information on the date the shock will occur. This information is most advantageous for very significant shocks but also for shocks with an "intermediaterisk" of occurrence. If an important shock occurs with very low conditional probability of immediate occurrence, there is still enought time to adapt to the shock and it is not worthwhile to acquire exact information on the date of the shock. On the other hand, if an important shock occurs with a very high conditional probability of immediate occurrence, there is not sufficient time to adapt to the shock and it is not worthwile to know the exact date of the shock. This may serve as one explanation for the non-monotonic relationship between $t_{a}$ and $\mathrm{D}$.

\subsection{Adaptation vs. non adaptation}

We also computed the optimal solutions for our problem when the water agency has no information about the date the shock will occur, that is, when the water agency does not adapt to the shock. It is not necessary to provide details on the analytical resolution of this case. It suffices only to say that the problem consists in considering two simple problems

\footnotetext{
${ }^{20}$ We would like to thank an anonymous referee for this interpretation.
} 

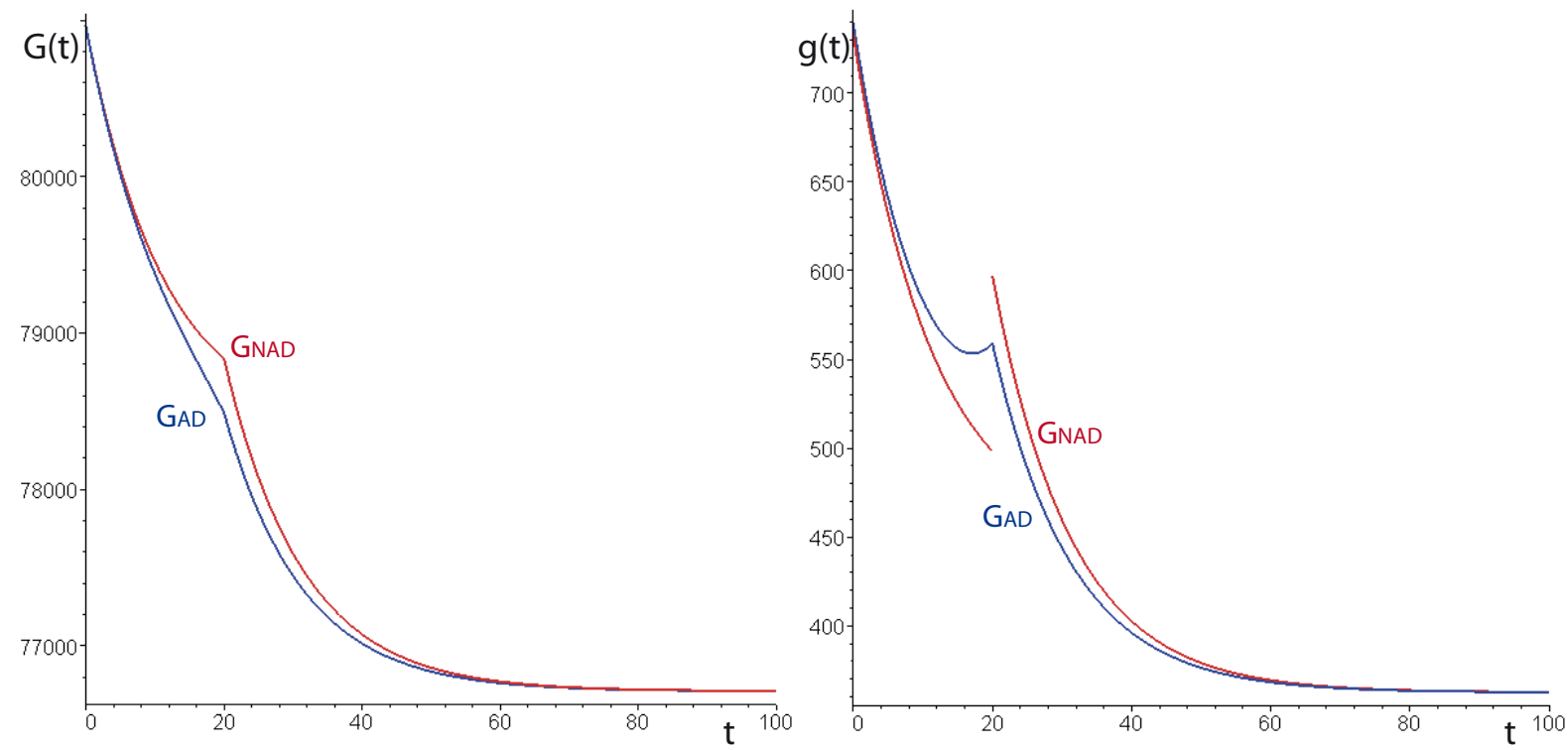

Figure 7: $G^{*}(t)$ in million cubic meters and $g^{*}(t)$ in million cubic meters per year for the problem of non-adaptation (in red) and adaptation (in blue) at $t_{a}=20$ years (left-hand side) for a shock of 70 million of cubic meters per year.

with infinite horizon for the two different periods of the problem. Indeed, when the water agency does not have any information about the shock until it happens, optimal behavior corresponds with optimal solutions to the simple problem (appendix A.1) with $r=r_{1}$, before the shock. Conversely, from the occurrence of the shock $\left(t_{a}\right)$, optimal behavior corresponds with optimal solutions to the simple problem, but now taking the value of the shock into account (i.e $\left.r=r_{2}\right)^{21}$.

In the following, we compare the situation with non-adaptation to the situation with adaptation. That is, we compare a case in which the water agency reacts only once the shock has occurred to a case in which the water agency adapts optimally to the shock (i.e. the deterministic shock in section 2.1). In figure 7, we compare optimal solutions of the stock $G^{*}(t)$ and extractions $g^{*}(t)$ for the adaptation case (in blue) and for the nonadaptation case (in red), when the value of the shock $\left(r_{2}=290 \mathrm{Mm}^{3} / \mathrm{yr}\right)$ and the date of the shock $\left(t_{a}=20\right.$ years) are fixed. We observe (on the right-hand side) that the resource is more intensively used when the shock is anticipated (in blue) than when it is not anticipated. For example, the stock level at $t_{a}$ in the case of total uncertainty exceeds the stock level in case of adaptation by about $345 \mathrm{Mm}^{3}$. However, in the long run, the stock level is

\footnotetext{
${ }^{21}$ We hence set $G_{2}\left(t_{a}\right)=G_{1}\left(t_{a}\right)$ with $G_{1}(t)$ optimal solution of the stock for the non-adaptation problem before $t_{a}$ and $G_{2}(t)$ optimal solution of the stock after $t_{a}$.
} 
the same for the two cases. Moreover, we observe (on the left-hand side) that extractions in the non-adaptation case are lower in the short run but higher in the long run than in the adaptation case.

Finally, we compute social welfare for the non-adaptation and adaptation cases using our above numerical example. We observe in Table 6 that losses due to non-adaptation are high in both the short and long run. For example, we see that total welfare losses from a lack of adaptation are around 47 million Euros. In particular, losses are around 4 millions of Euros in the short run and 43 million Euros in the long run.

As a result, it is useful for the water agency to account for information about the occurrence of the shock. Indeed, the water agency always does better if it anticipates the shock than if it reacts to the shock once it has already occurred: short-run, long-run and overall social welfare are lower in the case of non-adaptation than in the deterministic case.

\begin{tabular}{c|c|c|c} 
& {$\left[\mathbf{0}, t_{a}\right)$} & {$\left[t_{a}, \infty\right)$} & TOTAL \\
\hline non-adaptation & 219311 & 27195 & 246506 \\
adaptation & 222924 & 70392 & 293316
\end{tabular}

Table 6: Social welfare in thousands of Euros for the problem of non-adaptation and adaptation with $t_{a}=20$ years and for a shock of 70 million cubic meters per year.

\section{Conclusions and extensions}

We have shown that a deterministic shock to the recharge rate leads to an increase in extraction and social welfare in the short run (before the occurrence of the shock), and to a decrease in extractions and social welfare in the long run (in the steady state). The higher the value of the shock, the smaller the steady-state resource stock, which reduces extraction possibilities in the long run. The water agency hence adapts to anticipated losses incurred in the long run by accumulating gains in the short run. This compensating short-term behavior is more important the greater the shock and the later it occurs. Overall, the more intense the shock, the lower the total social welfare, and the later the shock occurs, the greater the total social welfare.

Likewise, a stochastic shock leads to an increase in extraction and social welfare in the short run and to a decrease in extractions and social welfare in the long run. Again, in the long run, steady-state resource stocks are lower in presence of a shock than without a shock. Hence, the water agency adapts in a similar way to the deterministic and the stochastic case (when comparing the stochastic case in which the expected value of the unknown date equals the known date of the deterministic case). 
However, there are some differences between the two problems. The long-run reduction in steady state resource stocks is smaller in the stochastic case than in the deterministic case. Moreover, the short-term compensating behavior is different: in the stochastic case, extractions are higher in the very short run and, fall below extractions in the deterministic case (before increasing again in the medium and long run). Overall, total social welfare is greater in the deterministic case than in the corresponding stochastic case.

We conclude that an increase in uncertainty leads to more conservative extraction in the long run and to more intensive extraction in the very short run. This adaptation behavior is more pronounced the higher the conditional probability of immediate occurrence. However, an increase in uncertainty also leads to less efficient water management: social welfare is lower in the stochastic case than in the deterministic case. For the water agency in the La Mancha basin, this means that it is always better to acquire information about the date of the regime shift than to adapt to a regime shift on a stochastic date.

More specifically, information acquisition is more important if future shocks are potentially important: the higher the value of the shock, the higher the gain from switching from the stochastic to the deterministic case. Furthermore, for a fixed intensity of potential shocks, information acquisition is greatest for intermediate "risks": for a very low conditional probability of immediate occurrence, there is still enough time to adapt to the shock, and it is not worthwhile to acquire exact information on the date of the shock; for a very high conditional probability of immediate occurrence, there is not sufficient time to appropriately adapt to the shock, and it is not worthwhile to know the precise date of the shock. Finally, we note that the water agency always does better if it anticipates the shock than if it reacts once the shock has occurred: short-run, long-run and overall social welfare are lower in the case of non-adaptation than in the deterministic or stochastic cases. Policy recommendations could thus consist in first estimating the occurrence probabilites of the shock and evaluating a more exact occurrence period (the "date") only if the event falls in the category of "high-intensity/intermediate-risk" events.

With respect to the literature, we confirm that an exogenous reversible shock leads to the "announcement effect" (see Di Maria et al. (2012) [7]) when the shock is deterministic. Additionally, we show that non-monotonic extraction behavior is optimal. We also confirm that an exogenous shock under uncertainty leads to more precautionary behavior in the long run and to increased extraction in the short run (see Tsur and Zemel (2012) [18]), compared to the risk-free situation, and we extend these results by comparing uncertain and deterministic cases and considering a reversible event occurring at an uncertain date.

There are several possible extensions to our paper. We could examine the impact of several successive changes in recharge rates: for example the recharge could decrease because of a decrease in precipitation or a more intensive use of resources by other users, 
as discussed above, but it could then increase, for example as a result of investment in alternative resources, such as desalinization plants. We could consider a case in which the conditional probability of occurrence is dependent on some element of the dynamic system, such as the past evolution of the recharge rate. In addition, we could consider the case in which the recharge rate is stochastic, instead of the occurrence date of the shock. Finally, uncertainty about the extent of climate change may diminish over time: if new information is acquired during the time period concerned, we would need a new optimization method that accounts for rolling horizons.

\section{A The model}

\section{A.1 Resolution of the simple problem}

The Hamiltonian of this problem is given by:

$$
H=\frac{a}{b} g-\frac{1}{2 b} g^{2}-(z-c G) g+\lambda(-(1-\alpha) g+r),
$$

where $\lambda$ is the adjoint variable. Applying the maximum principle and assuming interior solutions, we have the usual first order conditions:

$$
\begin{gathered}
\frac{\partial H}{\partial g}=0 \Rightarrow \frac{a}{b}-\frac{1}{b} g-(z-c G)-\lambda(1-\alpha)=0 \\
\dot{\lambda}=-\frac{\partial H}{\partial G}+\rho \lambda \Rightarrow \dot{\lambda}=-c g+\rho \lambda .
\end{gathered}
$$

From (19), we find the optimal extraction volume as a function of the resource stock and the shadow price:

$$
g=a-z b+c b G-\lambda b(1-\alpha) .
$$

Substituting (21) in the equations of motion of the state (3) and adjoint variable (20), we have the following dynamic system:

$$
\begin{gathered}
\dot{G}=r-(1-\alpha)(a-z b)-c b(1-\alpha) G+\lambda b(1-\alpha)^{2}, \\
\dot{\lambda}=c(a-z b)-c^{2} b G+(c b(1-\alpha)+\rho) \lambda,
\end{gathered}
$$

with $G(0)=G_{0}$, which allows us to find the roots of the characteristic polynom:

$$
\rho_{1,2}=\frac{\rho \pm \sqrt{\rho^{2}+4 c b(1-\alpha) \rho}}{2} .
$$

From equations (21), (22) and (23), for $\dot{G}=0$ and $\dot{\lambda}=0$, we find the steady state of the problem: 


$$
\begin{gathered}
g_{\infty}=\frac{r}{(1-\alpha)}, \\
\lambda_{\infty}=\frac{c r}{\rho(1-\alpha)}, \\
G_{\infty}=\frac{r}{c b(1-\alpha)}+\frac{r}{\rho}-\frac{a}{c b}+\frac{z}{c} .
\end{gathered}
$$

Since we assume that all parameters are positive, $g_{\infty}$ and $\lambda_{\infty}$ in equations (25) and (26) are always positive. Moreover, in what follows, we consider parameters such that $G_{\infty}$ (in equation (27)) is positive.

Finally, we have the optimal extraction paths, with $\rho_{2}$, the negative root:

$$
\begin{gathered}
G^{*}(t)=\mathrm{e}^{\rho_{2} \mathrm{t}}\left(\mathrm{G}_{0}-\mathrm{G}_{\infty}\right)+\mathrm{G}_{\infty} \\
g^{*}(t)=\frac{r}{(1-\alpha)}-\frac{\rho_{2}}{(1-\alpha)} \mathrm{e}^{\rho_{2} \mathrm{t}}\left(\mathrm{G}_{0}-\mathrm{G}_{\infty}\right), \\
\lambda^{*}(t)=\mathrm{e}^{\rho_{2} \mathrm{t}}\left(\lambda_{0}-\lambda_{\infty}\right)+\lambda_{\infty}
\end{gathered}
$$

and,

$$
\lambda_{0}=\frac{a}{b(1-\alpha)}-\frac{z-c G_{0}}{(1-\alpha)}-\frac{1}{b(1-\alpha)^{2}}\left(r-\rho_{2}\left(G_{0}-G_{\infty}\right)\right),
$$

which we find by combining equations (3) and (19).

\section{A.2 Resolution of the deterministic problem}

To solve this problem, we separate it into two parts and proceed by backward induction. First, we solve the maximization between $t_{a}$ and $\infty$, proceeding as in (A.1).

The steady state of the problem is:

$$
\begin{gathered}
g_{\infty}=\frac{r_{2}}{(1-\alpha)}, \\
\lambda_{\infty}=\frac{c r_{2}}{\rho(1-\alpha)} \\
G_{\infty}=\frac{r_{2}}{c b(1-\alpha)}+\frac{r_{2}}{\rho}-\frac{a}{c b}+\frac{z}{c}
\end{gathered}
$$

and we know that solutions can be written as follows:

$$
\begin{aligned}
G_{r_{2}}^{+}(t) & =\mathrm{e}^{\rho_{2}\left(\mathrm{t}-\mathrm{t}_{\mathrm{a}}\right)}\left(\mathrm{G}_{\mathrm{ta}}-\mathrm{G}_{\infty}\right)+\mathrm{G}_{\infty}, \\
\lambda_{r_{2}}^{+}(t) & =\mathrm{e}^{\rho_{2}\left(\mathrm{t}-\mathrm{t}_{\mathrm{a}}\right)}\left(\lambda_{\mathrm{ta}}-\lambda_{\infty}\right)+\lambda_{\infty},
\end{aligned}
$$




$$
g_{r_{2}}^{+}(t)=\frac{r_{2}}{1-\alpha}-\frac{\rho_{2}}{(1-\alpha)}\left(G_{t a}-G_{\infty}\right) \mathrm{e}^{\rho_{2}\left(\mathrm{t}-\mathrm{t}_{\mathrm{a}}\right)},
$$

with,

$$
\lambda_{t a}=\frac{a}{b(1-\alpha)}+\frac{-z+c G_{t a}}{(1-\alpha)}-\frac{r_{2}}{b(1-\alpha)^{2}}+\frac{1}{b(1-\alpha)^{2}} \rho_{2}\left(G_{t a}-G_{\infty}\right), \quad G_{t a} \quad \text { unknown. }
$$

Substituting (34) and (36) in problem (7), we can compute the scrap value, $\phi\left(G_{t a}\right)$ (see equation (7)), that is ${ }^{22}$ :

$$
\begin{gathered}
\phi\left(G_{t a}\right)=\sigma+\tau G_{t a}+v G_{t a}^{2}, \quad \text { with }^{23} \\
\tau=\frac{-r_{2} \rho(4 c b(1-\alpha)+\rho)+\rho^{2}(1-\alpha)(a-z b)+4 c b(1-\alpha)^{2} \rho(a-z b)}{\rho(1-\alpha)^{2} b(\eta+\rho+4 c b(1-\alpha))} \\
+\frac{\left.(2 c b(1-\alpha)+\rho) r_{2} \eta-\rho(1-\alpha) \eta(a-z b)\right)}{\rho(1-\alpha)^{2} b(\eta+\rho+4 c b(1-\alpha))}, \\
v=-\frac{c(-4 c b(1-\alpha)-\rho+\eta)}{(1-\alpha)(\eta+\rho+4 c b(1-\alpha))}, \quad \text { and } \\
\eta=\sqrt{\rho} \sqrt{\rho+4 b c(1-\alpha)} .
\end{gathered}
$$

We now turn to the second part of the problem, between 0 and $t_{a}$, considering the optimal solution for the first part. The Hamiltonian can be written as:

$$
H=\frac{a}{b} g-\frac{1}{2 b} g^{2}-(z-c G) g+\pi\left(-(1-\alpha) g+r_{1}\right),
$$

where $\pi$ is the adjoint variable. We are now in a free-endpoint problem, with $t_{a}$ known and need an additional transversality condition (see for example Léonard and Ngo van Long [11]):

$$
\pi\left(t_{a}\right)=\frac{\partial \phi\left(t a, G_{t a}\right)}{\partial G_{t a}}=2 v G_{t a}+\tau .
$$

Applying the maximum principle and assuming interior solutions, we have the usual first order conditions (19), (20) and the equations of motion of the state (3), with $r=r_{1}$. We have a system of differential equations:

$$
\dot{G}=r_{1}-(1-\alpha)(a-z b)-c b(1-\alpha) G+\pi b(1-\alpha)^{2},
$$

\footnotetext{
${ }^{22}$ We find that the expression $\phi\left(t a, G_{t a}\right)$ does not have the independent term $t_{a}$. In what follows, we write the scrap value function, $\phi\left(G_{t a}\right)$.

${ }^{23}$ We do not detail expression of $\sigma$ because it is not necessary for the resolution of the problem, but it is available from the authors upon request.
} 


$$
\dot{\pi}=c(a-z b)-c^{2} b G+(c b(1-\alpha)+\rho) \pi,
$$

and we know that the solutions of the finite problem are now, of the shape:

$$
\begin{aligned}
& G_{r_{2}}^{-}(t)=A_{1} \mathrm{e}^{\rho_{1} \mathrm{t}}+\mathrm{A}_{2} \mathrm{e}^{\rho_{2} \mathrm{t}}+\mathrm{A}_{3}, \\
& \pi_{r_{2}}^{-}(t)=B_{1} \mathrm{e}^{\rho_{1} \mathrm{t}}+\mathrm{B}_{2} \mathrm{e}^{\rho_{2} \mathrm{t}}+\mathrm{B}_{3},
\end{aligned}
$$

with,

$$
\begin{gathered}
G_{r_{2}}^{-}(0)=A_{1}+A_{2}+A_{3}=G_{0}, \\
\pi\left(t_{a}\right)=B_{1} \mathrm{e}^{\rho_{1} \mathrm{ta}}+\mathrm{B}_{2} \mathrm{e}^{\rho_{2} \mathrm{ta}}+\mathrm{B}_{3}=2 v \mathrm{G}_{\mathrm{ta}}+\tau,
\end{gathered}
$$

and $\rho_{1}, \rho_{2}$ described in equation $(24)$.

This constitutes a system of 6 equations and 6 unknowns, which we can solve to find optimal solutions for the problem for the first period, between 0 and $t_{a}$. We find optimal values of $A_{i}, B_{i}(i=1 . .3)^{24}$ :

$$
A_{i}=C_{1}^{i}+C_{2}^{i}\left(2 v G_{r}^{*}\left(t_{a}\right)+\tau\right), \quad \mathrm{i}=1,2,
$$

with,

$$
\begin{gathered}
C_{1}^{1}=\frac{b(1-\alpha)\left(\rho c\left(r_{1}+(1-\alpha) e^{\rho_{2} t_{a}}(a-z b)-r_{1} e^{\rho_{2} t_{a}}\right)-\rho_{2} c r_{1}+(1-\alpha) c^{2}\left(r_{1} b+e^{\rho_{2} t_{a}} \rho b G_{0}-r_{1} b e^{\rho_{2} t_{a}}\right)\right)}{D^{1}} \\
C_{2}^{1}=\frac{b(1-\alpha)^{2} \rho\left(\rho_{2}-\rho-c b(1-\alpha)\right)}{D^{1}}, \\
D^{1}=\rho\left((\rho 2-\rho) e^{\rho_{1} t_{a}} c b(1-\alpha)+c^{2} b^{2}(1-\alpha)^{2}\left(e^{\rho_{2} t_{a}}-e^{\rho_{1} t_{a}}\right)-c b(1-\alpha), \rho_{1} e^{\rho_{1} t_{a}}+\rho_{1} e^{\rho_{1} t_{a}}\left(\rho_{2}-\rho\right)\right) \\
C_{1}^{2}=\frac{-\left(c b(1-\alpha)+\rho-\rho_{2}\right)\left(\rho_{1} e^{\rho_{1} t_{a}} \rho\left((1-\alpha)(a-z b)-r_{1}\right)+c^{2} b^{2}(1-\alpha)^{2}\left(G_{0} \rho+r_{1}-r_{1} e^{\rho_{1} t_{a}}\right)\right.}{D^{2}} \\
\frac{\left.+c b(1-\alpha)\left(\left(G_{0} \rho-r_{1}\right) e^{\rho_{1} t_{a}} \rho_{1}-\rho r_{1} e^{\rho_{1} t_{a}}\right)+c b(1-\alpha)^{2} e^{\rho_{1} t_{a}} \rho(a-z b)\right)}{D^{2}} \\
C_{2}^{2}=\frac{\left(c b(1-\alpha)+\rho-\rho_{2}\right)\left(c b^{2}(1-\alpha)^{3} \rho\right)}{D^{2}},
\end{gathered}
$$

\footnotetext{
${ }^{24}$ We do not provide detailed solutions of $B_{i}(i=1 . .3)$ because the equations are too long and they are not necessary for the proofs, however, they are available from the authors upon request.
} 
$D^{2}=c b(1-\alpha) \rho\left(\left(\rho_{2}-\rho\right) c b(1-\alpha) e^{\rho_{1} t_{a}}+c^{2} b^{2}(1-\alpha)^{2}\left(e^{\rho_{2} t_{a}}-e^{\rho_{1} t_{a}}\right)-c b(1-\alpha) e^{\rho_{1} t_{a}} \rho_{1}-\rho e^{\rho_{1} t_{a}} \rho_{1}+e^{\rho_{1} t_{a}} \rho_{1} \rho_{2}\right)$,

and,

$$
A_{3}=-\frac{r_{1} \rho-\rho a+\rho z b+\rho \alpha a-\rho \alpha z b+c r_{1} b-c r_{1} b \alpha}{b \rho(\alpha-1) c} .
$$

Finally, we combine the solutions of the two periods such that $G_{r_{2}}^{-}\left(t_{a}\right)=G_{r_{2}}^{+}\left(t_{a}\right)$, and we obtain optimal solutions of stock $G_{r_{2}}^{*}(t)$ and extractions $g_{r_{2}}^{*}(t)$ for the deterministic problem.

\section{A.3 Resolution of the stochastic problem}

The Hamiltonian of the stochastic problem is:

$$
H=\frac{a}{b} g-\frac{1}{2 b} g^{2}-(z-c G) g+\theta \phi(G)+\gamma\left(r_{1}-(1-\alpha) g\right)
$$

with $\phi(G)$ described in $(37)$ and $\gamma$ the adjoint variable. Applying the maximum principle and assuming interior solutions, we have the usual first order conditions:

$$
\begin{gathered}
\frac{\delta H}{\delta g}=0 \Longrightarrow \frac{a}{b}-\frac{1}{b} g-(z-c G)-\gamma(1-\alpha)=0 \\
\dot{\gamma}=-\frac{\delta H}{\delta G}+(\rho+\theta) \gamma \Longrightarrow \dot{\gamma}=-c g-\theta \frac{\delta \phi(G)}{\delta G}+(\rho+\theta) \gamma \\
\Longrightarrow \dot{\gamma}=-c g-\theta(2 v G+\tau)+(\rho+\theta) \gamma
\end{gathered}
$$

From (47), we find the optimal extraction volume as a function of the resource stock and the shadow price:

$$
g=a-z b+c b G-\gamma b(1-\alpha) .
$$

Substituting (49) in the equations of motion of the state (15) and adjoint variable (48), we have the following dynamic system:

$$
\begin{gathered}
\dot{G}=r_{1}-(a-z b)(1-\alpha)-c b(1-\alpha) G+b(1-\alpha)^{2} \gamma, \\
\dot{\gamma}=-c(a-z b)-\theta \tau-\left(c^{2} b+2 \theta v\right) G+(c b(1-\alpha)+\rho+\theta) \gamma,
\end{gathered}
$$

where $G(0)=G_{0}$, which allows us to find the roots of the characteristic polynom:

$$
\nu_{1,2}=\frac{\rho+\theta}{2} \pm \frac{\sqrt{\rho^{2}+2 \rho \theta+\theta^{2}+4 b c(1-\alpha)(\rho+\theta)-8 b \theta v(1-\alpha)^{2}}}{2}
$$


From equations (49), (50) and (51), for $\dot{G}=0$ and $\dot{\gamma}=0$, we find the steady state of the problem:

$$
\begin{gathered}
g_{\infty}=\frac{r_{1}}{(1-\alpha)}, \\
\gamma_{\infty}=\frac{-c^{2} b r_{1}-\theta \tau c b(1-\alpha)+2 \theta v(1-\alpha)\left(a-z b-r_{1}\right)}{b(1-\alpha)(-c \rho-c \theta+2 \theta v(1-\alpha))}, \\
G_{\infty}=\frac{(a-z b)(1-\alpha)(\rho+\theta)-r_{1}(\rho+\theta)-c b(1-\alpha) r_{1}-b(1-\alpha)^{2} \theta \tau}{b(1-\alpha)(-c \rho-c \theta+2 \theta v(1-\alpha))},
\end{gathered}
$$

with $\tau$ and $v$ described in equations (38) and (39). We consider parameters such that $G_{\infty}$ and $g_{\infty}$ (in equations (55) and (53)) are positive.

Finally, we have the optimal extraction paths, with $\nu_{2}$, the negative root:

$$
\begin{gathered}
G_{r_{2}^{S}}^{*}(t)=\mathrm{e}^{\nu_{2} \mathrm{t}}\left(\mathrm{G}_{0}-\mathrm{G}_{\infty}\right)+\mathrm{G}_{\infty}, \\
g_{r_{2}^{S}}^{*}(t)=\frac{r_{1}}{(1-\alpha)}-\frac{\nu_{2}}{(1-\alpha)} \mathrm{e}^{\nu_{2} \mathrm{t}}\left(\mathrm{G}_{0}-\mathrm{G}_{\infty}\right),
\end{gathered}
$$

with $G_{\infty}$ described in equation (55).

\section{A.4 Proof of propositions}

\section{A.4.1 Proposition 2.2: $G_{r}^{*}\left(t_{a}\right)$ is a increasing monotonous function of $r$.}

\section{Proof :}

We seek to prove that $\frac{\delta G_{r}^{*}\left(t_{a}\right)}{\delta r}>0$.

As we prove in appendix A.2,

$$
\begin{gathered}
\phi(G)=\sigma+\tau G_{r}^{*}\left(t_{a}\right)+v G_{r}^{*}\left(t_{a}\right)^{2}, \\
\pi(t a)=G_{r}^{*}\left(t_{a}\right)+2 v G_{r}^{*}\left(t_{a}\right), \\
G_{r}^{*}\left(t_{a}\right)=A_{1} \mathrm{e}^{\rho_{1} \mathrm{t}_{\mathrm{a}}}+\mathrm{A}_{2} \mathrm{e}^{\rho_{2} \mathrm{t}_{\mathrm{a}}}+\mathrm{A}_{3},
\end{gathered}
$$

and,

$$
A_{i}=C_{1}^{i}+C_{2}^{i}\left(2 v G_{r}^{*}\left(t_{a}\right)+\tau\right), \quad \mathrm{i}=1,2,
$$

where $v$ and $\tau$ are functions of $r, C_{2}^{i}(i=1,2)$, and $A_{3}$ are functions that does not depend on $r$.

The derivative of $G_{r}^{*}\left(t_{a}\right)$ with respect to $r$ is then, 


$$
\frac{\delta G_{r}^{*}\left(t_{a}\right)}{\delta r}=\frac{\delta A_{1}}{\delta r} e^{\rho_{1} t_{a}}+\frac{\delta A_{2}}{\delta r} \mathrm{e}^{\rho_{2} \mathrm{t}_{\mathrm{a}}}
$$

with,

$$
\frac{\delta A_{i}}{\delta r}=C_{2}^{i}\left(2 \frac{\delta v}{\delta r} G_{r}^{*}\left(t_{a}\right)+2 v \frac{\delta G_{r}^{*}\left(t_{a}\right)}{\delta r}+\frac{\delta \tau}{\delta r}\right) .
$$

Substituing the value $G_{r}^{*}\left(t_{a}\right)$ (equation (60)) in equation (63) and rearranging equation (62), we obtain,

$$
\frac{\delta G_{r}^{*}\left(t_{a}\right)}{\delta r}=\frac{M 1\left(e^{\rho_{1} t_{a}}-e^{\rho_{2} t_{a}}\right) e^{-\rho_{1} t_{a}}}{M 2},
$$

with,

$$
\begin{gathered}
M 1=2(1-\alpha)^{2} c^{2} b^{2} \sqrt{\rho+4 b(1-\alpha) c}, \\
M 2=(\rho+4 b(1-\alpha) c) \sqrt{\rho}\left(3 b(1-\alpha) c \rho+b(1-\alpha) c \eta+\rho^{2}+\eta \rho\right),
\end{gathered}
$$

and, $\rho_{1}>0, \rho_{2}<0$ and $\eta>0$, as described in equations (24) and (40).

As all parameters of the model are positive, expressions of $M 1, M 2$ and $\eta$ in equations (65), (66), and (40) respectively, are positive expressions. Thus, the right-hand side of equation (64) is greater than 0 , and $\frac{\delta G_{r_{2}}^{*}\left(t_{a}\right)}{\delta r_{2}}>0$.

\section{A.4.2 Proposition 2.3: $g_{r}^{*}(0)$ is a decreasing monotonous function of $r$.}

Proof We have to prove that $\frac{\delta g_{r}^{*}(0)}{\delta r}<0$.

Substituing the derivate of equation (43) in equation (8) of the dynamics of the aquifer, we obtain $g_{r}^{*}(t)$. Evaluating this function in $\mathrm{t}=0$, we see that,

$$
g_{r}^{*}(0)=\frac{1}{1-\alpha}\left(r_{1}-\rho_{1} A_{1}-\rho_{2} A_{2}\right) .
$$

The derivative with respect to $\mathrm{r}$ is then,

$$
\frac{\delta g_{r}^{*}(0)}{\delta r}=-\frac{1}{1-\alpha}\left(\rho_{1} \frac{\delta A_{1}}{\delta r}+\rho_{2} \frac{\delta A_{2}}{\delta r}\right),
$$

with $\frac{\delta A_{i}}{\delta r}(i=1,2)$ described in equation (63).

Substituing values of the functions in the right-hand part of equation (67), we obtain,

$$
\frac{\delta g_{r}^{*}(0)}{\delta r}=\frac{N 1 * N 2}{N 3 * N 4 * N 5},
$$


with,

$$
\begin{gathered}
N 1=4 c^{2} b^{2}(1-\alpha)^{2} \\
N 2=-c^{2} b^{2}(1-\alpha)^{2}\left(\eta\left(5-e^{-\eta t_{a}}\right)+\rho\left(13-e^{-\eta t_{a}}\right)\right)-c b(1-\alpha)\left(5 \rho \eta+7 \rho^{2}\right) \\
-\rho^{3}-\eta \rho^{2}-4 c^{3} b^{3}(1-\alpha)^{3}\left(1-e^{-\eta t_{a}}\right), \\
N 3=4 c b(1-\alpha) \rho e^{\rho_{1} t_{a}}+2 c b(1-\alpha) \eta e^{\rho_{1} t_{a}}+2 c^{2} b^{2}(1-\alpha)^{2}\left(e^{\rho_{1} t_{a}}-e^{\rho_{2} t_{a}}\right)+\rho^{2} e^{\rho_{1} t_{a}}+\rho \eta e^{\rho_{1} t_{a}}, \\
N 4=\eta+\rho+4 c b(1-\alpha), \\
N 5=3 c b(1-\alpha) \rho+c b(1-\alpha) \eta+\rho \eta+\rho^{2},
\end{gathered}
$$

and, $\eta>0, \rho_{1}>0, \rho 2<0$ described in equations (24) and (40).

Since we assume that all parameters of the model are positive, the expressions $N 1, N 3$, $N 4$, and $N 5$ in equations (69), (71), (72), and (73) respectively, are positive expressions, and $N 2$ in equation (70) is a negative expression. Thus, the right-hand side of equation (68) is less than 0 , and $\frac{\delta g_{r}^{*}(0)}{\delta r}<0$.

\section{A.4.3 Proposition 2.4: $g_{r}^{*}\left(t_{a}\right)$ is a decreasing monotonous function of $r$.}

Proof We seek to prove that $\frac{\delta g_{r}^{*}\left(t_{a}\right)}{\delta r}<0$.

Proceeding as in appendix A.4.2, but evaluating in $t=t_{a}$, we write,

$$
\frac{\delta g_{r}^{*}\left(t_{a}\right)}{\delta r}=-\frac{1}{1-\alpha}\left(\rho_{1} \frac{\delta A_{1}}{\delta r} e^{\rho_{1} t_{a}}+\rho_{2} \frac{\delta A_{2}}{\delta r}\right) e^{\rho_{2} t_{a}},
$$

with $\frac{\delta A_{i}}{\delta r}(i=1,2)$ described in equation (63).

Substituing values of the functions in the right-hand part of equation (74), we obtain,

$$
\frac{\delta g_{r}^{*}\left(t_{a}\right)}{\delta r}=\frac{D 1 * D 2}{D 3},
$$

with,

$$
D 1=-c^{2} b^{2}(1-\alpha),
$$




$$
\begin{gathered}
D 2=(4 c b(1-\alpha)+\rho)\left(1+e^{-\eta t_{a}}\right)+\left(1-e^{-\eta t_{a}}\right) \eta, \\
D 3=7 c b(1-\alpha) \rho^{2}+4 c^{2} b^{2}(1-\alpha)^{2}(3 \rho+\eta)+\rho^{\frac{3}{2}} \eta+5 c b(1-\alpha) \rho \eta+\rho^{3},
\end{gathered}
$$

and $\eta>0$ (see equation 40$)$.

Since we assume that all parameters of the model are positive, the expression $D 1$ in equation (76) is a negative expression, and expressions D2 and D3 in equations (77) and (78), respectively, are positive expressions. Thus, the right-hand side of equation (75) is less than 0 , and $\frac{\delta g_{r}^{*}\left(t_{a}\right)}{\delta r}<0$.

\section{A.4.4 Proposition 2.6: $G_{r^{S}}^{*}(\infty)$ (and $g_{r S}^{*}(\infty)$ ) are increasing monotonic (and constant) functions of $r$.}

Proof We seek to prove that $\frac{\delta G_{r S}^{*}(\infty)}{\delta r}>0$ and $\frac{\delta g_{r S}^{*}(\infty)}{\delta r}=0$.

First, if we derive equation (55) with respect to $r$, we see that,

$$
\frac{\delta G_{r^{S}}^{*}(\infty)}{\delta r}=\frac{-(1-\alpha) \theta \frac{\delta \tau}{\delta r}}{(-c \rho-c \theta+2 \theta v(1-\alpha))} .
$$

with $v$ (equation (39)), a function of $\mathrm{r}$.

Deriving $\tau$ (equation (38)) with respect to $\mathrm{r}$ and substituting this in (79),

$$
\frac{\delta G_{r^{S}}^{*}(\infty)}{\delta r}=\frac{\theta * S 1}{S 2}
$$

with,

$$
\begin{gathered}
S 1=\rho(\eta-\rho)+q(\eta-2 \rho) \\
S 2=\rho b c(1-\alpha)\left(\rho \eta+\rho^{2}+4 \rho b c(1-\alpha)+2 \theta \rho\right), \\
q=2 c b(1-\alpha)
\end{gathered}
$$

and $\eta>0$ as described in equation (40). Assuming all parameters are positive, we see that $q>0$ and hence $S 2>0$. It remains to be demonstrated that $S 1>0$.

$$
S 1>0 \Longleftrightarrow \rho(\eta-\rho)+q(\eta-2 \rho)>0 \Longleftrightarrow \rho \eta+q \eta>\rho^{2}+2 q \rho \Longleftrightarrow \eta>\frac{\rho(2 q+\rho)}{\rho+q}
$$

As $\eta=\sqrt{\rho} \sqrt{\rho+2 q}$, (see equation $(40)$ ), 


$$
\begin{aligned}
& \eta>\frac{\rho(2 q+\rho)}{\rho+q} \Longleftrightarrow \sqrt{\rho} \sqrt{\rho+2 q}>\frac{\rho(2 q+\rho)}{\rho+q} \Longleftrightarrow \rho^{2}+2 q \rho>\frac{\rho^{2}(2 q+\rho)^{2}}{(\rho+q)^{2}} \\
& \Longleftrightarrow\left(\rho^{2}+2 q \rho\right)(\rho+q)^{2}>\rho^{2}\left(4 q^{2}+4 q \rho+\rho^{2}\right) \\
& \Longleftrightarrow \rho^{4}+2 q \rho^{3}+q^{2} \rho^{2}+2 q \rho^{3}+4 q^{2} \rho^{2}+2 q^{3} \rho>4 \rho^{2} q^{2}+4 q \rho^{3}+\rho^{4} \Longleftrightarrow q^{2} \rho^{2}+2 q^{3} \rho>0 .
\end{aligned}
$$

As $q^{2} \rho^{2}+2 q^{3} \rho$ is always a positive expression, S1>0 and thus, $\frac{\delta G_{r S}^{*}(\infty)}{\delta r}>0$.

Finally, we can see from equation $(53)$ that $\frac{\delta g_{r S}^{*}(\infty)}{\delta r}=0$.

\section{A.4.5 Proposition 2.7: $G_{r S}^{*}(\infty)$ (and $g_{r S}^{*}(\infty)$ ) are decreasing monotonic (and constant) functions of $\theta$.}

Proof We seek to prove that $\frac{\delta G_{r S}^{*}(\infty)}{\delta \theta}<0$ and $\frac{\delta g_{r S}^{*}(\infty)}{\delta \theta}=0$.

First, if we derive equation (55) with respect to $\theta$, we see that,

$$
\frac{\delta G_{r^{*}}^{*}(\infty)}{\delta \theta}=2\left(r_{1}-r_{2}\right) \frac{T 1}{T 2}
$$

with,

$$
\begin{gathered}
T 1=(\rho+4 c b(1-\alpha))(\rho-\eta), \\
T 2=\rho^{2}+\rho(\eta+4 c b(1-\alpha))+2 \eta \theta .
\end{gathered}
$$

By assumption $r_{1}-r_{2}>0$, all parameters are positive, and from the expression of $\eta$ in (40), we see that $\rho<\eta$, and thus, T1<0 and T2 $>0$.

Hence, the right-hand part of equation $(80)$ is smaller than 0 , and $\frac{\delta G_{r S}^{*}(\infty)}{\delta \theta}<0$.

Finally, we see from equation $(53)$ that $\frac{\delta g_{r}^{*}(\infty)}{\delta \theta}=0$. 


\section{References}

[1] Amigues, J.-P., Debaeke, P., Itier, B., Lemaire, G., Seguin, B., Tardieu, F. et Thomas, A., 2006. Sécheresse et agriculture - réduire la vulnérabilité de l'agriculture à un risque accru de manque d'eau. Expertise scientifique collective, INRA, MAP

[2] Brozovic, N., Schlenker, W., 2011, Optimal management of an ecosystem with an unknown threshold, Ecological economics, 70, 627-640.

[3] Clarke, H., R., Reed, W., J., 1994, Consumption/pollution tradeoffs in an environmental vulnerable to pollution-related catastrophic collapse, Journal of Economics Dynamics and Control, 18, 991-1010.

[4] Cummings, R. G., 1971, Optimum Exploitation of Groundwater Reserves with Saltwater Intrusion, Water Resources Research 7 (6), 1415-1424.

[5] Dasgupta, P.,Heal, G., 1974, The Optimal Depletion of Exhaustible Resources, The revue of economic studies, 41, 3-28.

[6] de Zeeuw, A., Zemel, A., 2012, Regime shifts and uncertainty in pollution control, Journal of Economic Dynamics and Control, 36, 939-950.

[7] Di Maria, C., Smulders, S., van der Werf, E., 2012, Absolute abundance and relative scarcity: Environmental policy with implementation lags, Ecological Economics, 74, 104-119.

[8] Esteban, E., Albiac, J., 2011, Groundwater and ecosystems damages: Questioning the Gisser-Sanchez effect, Ecological Economics 70, 2062-2069.

[9] Esteban, E., Dinar, A., 2012, Groundwater-dependent ecosystems: How does the type if ecosystem affect the optimal management strategy, Working paper.

[10] Gisser, M., Sanchez, D.A., 1980, Competition versus optimal control in groundwater pumping, Water Resources Research 31, 638-642.

[11] Léonard, D., Long, N.V., 1992, Optimal Control Theory and Static Optimization in Economics, Cambridge University Press, 353 p.

[12] López-Gunn, E., 2012, Groundwater governance and social capital, Geoforum 43, 1140-1151.

[13] Roseta-Palma, C., 2002, Groundwater Management When Water Quality Is Endogenous, Journal of Environmental Economics and Management 44, 93-105.

[14] Roseta-Palma, C., 2003, Joint Quantity/Quality Management of Groundwater, Environmental and Resource Economics 26, 89-106. 
[15] Tsur, Y., Zemel, A., 1995, Uncertainty and irreversibility in groundwater resource management, Journal of Environmental Economics and Management, 29,149-161.

[16] Tsur, Y., Zemel, A., 1996, Accounting for global warming risks: Resource management under event uncertainty, Journal of Economic Dynamics and Control, 20, 1289-1305.

[17] Tsur, Y., Zemel, A., 2004, Endangered aquifers: Groundwater management under threats of catastrophic events, Water Resources Research 40, 1-10.

[18] Tsur Y. and Zemel A., 2014, Dynamic and stochastic analysis of environmental and natural resources. In: Handbook of Regional Science, M.M. Fischer and P. Nijkamp (eds.) Chapter 47, pp. 929-949, Springer.

[19] Zemel, A., 2012, Precaution under mixed uncertainty: Implications for environmental management, Resource and Energy Economics, 34, 188-197.

[20] Zilberman, D., Dinar, A., MacDougall, N., Khanna, M., Brown, C., Castillo, F., 2003, Individual and institutional responses to the drought: the case of california agriculture, Working Paper, Dept. of Agr. and Res. Econ., University of California, Berkeley. 